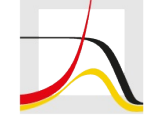

MAX PLANCK INSTITUTE

FOR DEMOGRAPHIC RESEARCH

Konrad-Zuse-Strasse 1 · D-18057 Rostock · Germany · Tel +49 (0) 3812081 - 0 · Fax +49 (0) 3812081 - $202 \cdot$ www.demogr.mpg.de

MPIDR Working Paper WP 2022-009 I February 2022

https://doi.org/10.4054/MPIDR-WP-2022-009

\title{
Leadership skills and completed fertility among males. A study based on data from Swedish registries
}

Steffen Peters I peters@demogr.mpg.de

Kieron Barclay I barclay@demogr.mpg.de

This working paper has been approved for release by: Peter Eibich (eibich@demogr.mpg.de),

Deputy Head of the Research Group Labor Demography.

(c) Copyright is held by the authors.

Working papers of the Max Planck Institute for Demographic Research receive only limited review. Views or opinions expressed in working papers are attributable to the authors and do not necessarily reflect those of the Institute. 


\title{
Leadership skills and completed fertility among males. A study based on data from Swedish registries
}

\author{
Steffen Peters ${ }^{1,2}$, Kieron Barclay ${ }^{1,2,3}$ \\ ${ }^{1}$ Max Planck Institute for Demographic Research \\ ${ }^{2}$ Stockholm University \\ ${ }^{3}$ Swedish Collegium for Advanced Study
}

\begin{abstract}
Human beings tend to organize themselves in social groups with hierarchical structures. Leadership skills (LS) increase the chances of ascending to a higher rank in such hierarchies, which allows individuals to provide greater support for a partner and, eventually, a potential child. Research on the association between LS and fertility outcomes has been relatively scarce though. Our study increases the understanding of this correlation by exploring the prospective association of LS on completed fertility (number of children, childlessness) based on population data from Sweden. Poisson regression and Linear Probability models were applied for this purpose. Additionally, analyses using fixed effects models examine potential differences between within- and between-family considerations. Our findings demonstrate a positive association between LS measured at age of assignment to military service (17-20 years) and number of children by age 39 or later. In addition, men with lower LS scores are more likely to remain childless. Stratifications by potential mediators reveal that patterns are particularly clear among males of lowest income deciles, highest education, and those who have never been married. Males in higher income deciles, the lowest educational group, or who have ever been married do not have large fertility differences by LS scores. Further research is still needed for a better understanding of the personality-fertility link, e.g. whether personality characteristics are associated with the timing of childbearing, or whether similar results can be found in other cultures.
\end{abstract}

\section{Introduction}

In contemporary societies, many social groups are hierarchically structured. Individuals may aim for a higher social position in this structure for various reasons. For instance, more resources are available in higher positions and can help to support families and partners. Previous research has explored the extent to which indicators of the individual's socio- 
economic status (SES) are linked with family formation processes (Liefbroer \& Corijn, 1999; Shafer \& James, 2013; van Wijk et al., 2021), and in particular with fertility (Bar et al., 2018; Begall, 2013; Dribe et al., 2017; Gray \& Evans, 2019; Impicciatore \& Tomatis, 2020; Jalovaara et al., 2019; Sobotka et al., 2017). Associations with fertility differ according to SES indicators and cultures of interest. For instance, higher educational levels reveal negative associations with fertility in many high-income countries (Begall, 2013; Skirbekk, 2008) whereas positive correlations between educational level and fertility have been found in the Nordic countries, and in particular among males (Jalovaara et al., 2019). However, the association between factors that predict SES and, therefore, the chances to reach a higher position on the one side and fertility outcomes on the other has received less attention. There are some personality facets such as extraversion, conscientiousness or neuroticism that have been explored with regards to fertility outcomes (Jokela, 2012; Jokela et al., 2011; Skirbekk \& Blekesaune, 2014; Tavares, 2016). Leadership skills (LS) have been neglected although they determine career outcomes (Floris et al., 2020; Maurer et al., 2017) such as earnings (Kuhn \& Weinberger, 2005; Lund et al., 2007) and the probability of promotion (Kragt \& Day, 2020; Maurer et al., 2017). Therefore, LS may be linked with family formation processes via SES characteristics. However, the extent to which LS influences family formation is not well-explored. To the best of our knowledge, only one study by Jokela and Keltikangas-Järvinen (2009) has looked at the prospective association between LS in adolescence and the probability of having a first, second, and third child by age 39. Weaim to extend this research by a) considering completed fertility as total number of children and probability to remain childless by age 39 and higher, b) using data on the full male population from Swedish registers, and c) examining the mediating role of income, education, and marital status for the LS-fertility link.

\section{Theoretical Background}

\section{Personality and fertility}

The association between personality and fertility is very complex since personality consists of a number of facets. It involves the individual's way of thinking, emotions and behaviors but also cognitive and motivational aspects (Uher 2017). These facets accompany each individual throughout life, and have, therefore, an impact on different decisions. One of the most important decisions over the life course relates to childbearing. Fertility intentions depend on a number of factors (McAllister et al., 2016), e.g. expected costs of children (Liefbroer, 2005), the social network that can provide support (Bernardi \& Klaerner, 2014) or the current working situation (Kaufman \& Bernhardt 2012). The personality of individuals might play an important role regarding all these aspects and deciding over childbearing. Hutteman et al. (2013), for 
instance, have found positive correlations between self-esteem and fertility for both genders whereas shyness is not linked with fertility among men or women. The most widely accepted measure of personality is the Five Factor Model (FFM), which includes the personality dimensions 'agreeableness', 'conscientiousness', 'extraversion', 'neuroticism', and 'openness' (McCrae \& Costa, 1987). Several studies have examined the association between these factors and fertility suggesting that, for instance, agreeableness and, in particular, extraversion are positively linked with childbearing (e.g. Jokela et al., 2011; Peters, 2022; Tavares, 2016).

However, other personality facets such as leadership skills (LS) have been neglected regarding fertility outcomes. Therefore, with our study, we aim to increase the understanding of the association between LS and fertility.

\section{SES and fertility}

From an evolutionary perspective, a higher position in hierarchical structures is linked with a number of benefits, e.g. higher chances to survive and reproduce (Cummins, 2006). Based on evolutionary developed strategies, the social position seems to be particularly important for the reproduction success of males (Cummins, 2006). Evolutionary psychologists have argued that women search for male partners who may provide them (and potential children) with resources and protection (Buss, 1994, 2006; Cummins, 2006). This hypothesis is supported by previous research suggesting that individuals are more likely to initiate a relationship to somebody if they expect that person to receive a higher income in future (Eastwick \& Finkel, 2008). According to evolutionary anthropologists, this strong desire of women for resources and support is based on their greater investments of time and effort into reproduction (pregnancy, lactation) (Buss, 2006; Cummins, 2006). Indeed, findings from several studies indicate that socio-economic status is positively associated with fertility in pre-industrial societies (BobergFazlic et al., 2011), and in particular among males (Clark \& Cummins, 2015; Clark \& Hamilton, 2006; Low, 1990). On the other hand, some evidence suggests that higher SES groups did not have higher fertility in pre-industrial societies (Dribe et al., 2017), and previous findings may be attributable to studying net fertility, which focuses on surviving children instead of actual births (Dribe et al., 2017).

With respect to modern societies, different associations have been found. While the link between fertility and occupation/income has experienced a reversal from being positive to rather negative (or not significant at all) during fertility declines in high-income societies, the negative association between fertility and education has persisted for a long time (Skirbekk, 2008). These findings are supported by a number of studies among women from high-income countries, which suggest a negative association between fertility outcomes and socio- 
economic status such as income (Caucutt et al., 2002; Hopcroft, 2015; Jones \& Tertilt, 2006), education (Amin \& Behrman, 2014; Begall, 2013; Cygan-Rehm \& Maeder, 2013; Monstad et al., 2008; Skirbekk, 2008; Sobotka et al., 2017; Tropf \& Mandemakers, 2017), or occupation status (Begall, 2013). Nevertheless, there is also evidence that earnings are positively linked with fertility (Vikat, 2004). Regarding males, previous findings indicate a positive relationship between SES and fertility (Andersson \& Scott, 2007; Fieder et al., 2005; Hopcroft, 2006), in particular in the Nordic countries (Jalovaara et al., 2019; Kolk, 2019; Kolk \& Barclay, 2021). In a recent study, Jalovaara and colleagues (2019) demonstrate that low education is linked with lower fertility and higher levels of childlessness among males across Scandinavian countries. In line with these findings, previous studies suggest higher sexual activity among males of higher social status (Kanazawa, 2003; Pérusse, 1993). As the literature review above shows, higher social positions bring a number of benefits for individuals, and in particular for males. This also applies to childbearing, for which positive correlations with SES have been found among males in Sweden and other Nordic countries.

\section{Leadership skills and fertility}

Leadership skills (LS) are positively linked with the chances to reach a higher status and, therefore, may promote family formation processes. A previous study by Jokela and Keltikangas-Järvinen (2009) supports this hypothesis. The authors find that higher leadership scores are positively linked with higher probabilities of getting a first, second, and third child among both men and women (Jokela \& Keltikangas-Järvinen, 2009). Based on these findings and the theoretical explanations regarding associations with the SES, we expect to find positive correlations between LS and fertility in our study as well. However, we can make use of some important advantages based on the data. For instance, in our study we may draw conclusions on the population level due to the power of Swedish registry data; Jokela and KeltikangasJärvinen used information on approximately 1,300 individuals from the population-based study 'Cardiovascular Risk in Young Finns'. Furthermore, Jokela and Keltikangas-Järvinen could follow their participants for 18 years but the youngest individuals were 12 years of age at the first observation, i.e. they were followed until age 30, when fertility is often incomplete. However, we can follow individuals throughout almost the entire fertility history starting at young ages from military recruitment (17-20 years) until age 39 and higher. Due to the information from Swedish registers, we can control for factors such as cumulated income by age 39 whereas Jokela and Keltikangas-Järvinen could only include some characteristics (fertility, marital status, education etc.) in 3-year, 6-year and 9-year time intervals, respectively. Furthermore, register data allows us to consider family background by comparing siblings, which is not possible by using data from Cardiovascular Risk in Young Finns. 


\section{LS and income}

Leadership skills may influence fertility via a number of mechanisms, e.g. through socioeconomic status (SES), which is usually related to access to goods and resources, and determines the support for a family as a consequence (Cummins, 2006). Previous research suggests a positive association between leadership skills (LS) and SES. For instance, there is evidence that managers consider job applicants to fit better to a job if they demonstrate higher LS (Stone et al., 2018). In addition, Maurer and colleagues (2017) present findings from path analyses indicating that motivation to develop leadership skills can increase leadership capacity, and this may be linked with increasing income. Other studies come to similar conclusions, finding that higher positions require higher leadership skills (Mumford et al., 2000). This is in line with previous research that has found a positive association between leadership facets and income in Norway (Lund et al., 2007). With respect to our study design, findings from Kuhn and Weinberger (2005) are of particular interest since they examine the association between leadership indicators in adolescence on the one side (similar to our study) and occupational positions as well as income in young adulthood on the other (in our study: fertility). The authors find a positive relationship between holding leading positions in high school (e.g. captain of a sports team, president of a club) and the likelihood to get a managerial position 9-13 years after leaving high school (Kuhn \& Weinberger, 2005).

A number of previous studies have shown that income is associated with fertility. With particular regards to men in high-income countries, these associations are mostly positive. For instance, a positive relationship between income and number of children has been found among males in the US (Hopcroft, 2006, 2015) and the UK (Nettle \& Pollet, 2008). Furthermore, income is positively associated with the probability of getting a first and a second child among men in the US (Stulp et al., 2016). However, there is evidence that the positive association between income and fertility has attenuated over time in both the US (Bar et al., 2018) and European countries (Skirbekk, 2008). Positive associations between income and childbearing can also be found in the Nordic countries (Andersson \& Scott, 2007; Jalovaara \& Fasang, 2020). For instance, recent research has shown that Swedish men with lower incomes are more likely to remain childless by age 40 and this relationship has persisted across cohorts (Chudnovskaya, 2019). Additionally, higher cumulated earnings up to middle adulthood are connected with higher offspring counts across cohorts in Sweden (Kolk, 2019; Kolk \& Barclay, 2021). Kolk and Barclay (2021) furthermore explored the mediating role that income can take regarding the association between $\mathrm{IQ}$ and fertility. The authors have found that income can at least partly explain the variation in this link (Kolk \& Barclay, 2021) and, similar to our study, may serve as mediator. 


\section{LS and education}

In addition to income, we consider education as potential mediator for the LS-fertility link. Previous findings indicate that personality traits such as conscientiousness may predict educational outcomes (Damian et al., 2015; Meyer et al., 2019). There is some evidence indicating that education may not predict personality change well (Leikas \& Salmela-Aro, 2015) but also evidence for an effect of more years of educational increasing factors such as openness (Sutin et al., 2017). With specific regards to LS, literature suggests that there are differences according to educational level. For instance, Horishna et al. (2019) show that social work graduates score higher on LS than under-graduates from the same field do. However, it remains unknown whether this correlation is based on education or potential age effects. Furthermore, full-time students reveal higher LS scores than part-time students (Horishna et al., 2019). These analyses are based on cross-sectional data and, therefore, it remains unclear whether these associations can be considered to be causal and if so, in which direction. Lund and colleagues (2007) provide further evidence from Norway that LS are positively associated with educational level.

Furthermore, previous research has shown that lowest educational levels are linked with lowest cohort fertility rates among males from Sweden and the other Scandinavian countries (Jalovaara et al., 2019). In other contexts, a negative association between education and fertility has persisted for a long time across regions from all over the world (Skirbekk, 2008). The negative education-fertility link has also been shown in a more recent study by Sobotka and colleagues (2017) who find that higher educational groups reveal lowest cohort fertility rates among women of low-fertility countries from different regions of the world. Furthermore, evidence from Norway suggests that higher education is linked with delays in timing of first childbirth among women (Monstad et al., 2008). The authors come to this conclusion although completed fertility does not vary so much according to educational level (Monstad et al., 2008), which is consistent with findings from Jalovaara and colleagues (2019) among younger female birth cohorts in most of the Nordic countries.

\section{LS and marital status}

Another important mediator to consider is marital status. Previous research has demonstrated that personality traits such as neuroticism, self-esteem (Neyer \& Asendorpf, 2001), or extraversion (Sodermans et al., 2017) are associated with subsequent relationship status, but civil status does not seem to predict personality changes to a great extent (Neyer \& Asendorpf 
2001; Specht et al. 2011). However, the connection between divorce and personality is unclear (Bleidorn et al. 2018). LS may increase the probability to marry over the life course, which may also affect fertility outcomes. However, research on this specific question is scarce.

One way how LS might influence marital status is via mediators of SES. As shown above, LS are positively linked with SES, i.e. higher LS are linked with higher earnings, higher education, and better career outcomes. These SES indicators, in turn, are positively linked with the transition into marriage as shown by previous research for the US context (Shafer \& James, 2013). The correlation appears to be particularly strong among males. For instance, Kanazawa (2003) has shown that men from the US with lower incomes reveal higher risks to remain unmarried over time. Similarly, several studies have shown that, among men in high-income societies, income is positively associated with the onset of a serious relationship (Rapp, 2018), the entry into cohabitation/marriage (Clarkberg, 1999; Kalmijn, 2011), and into marriage (Burgess et al., 2003; Kuo \& Raley, 2016; McClendon et al., 2014; Schneider, 2011; Schneider et al., 2018; Shafer \& James, 2013).

Furthermore, a number of studies indicate a positive association between education and union formation (Sassler \& Lichter, 2020). In particular, previous research from the US suggests such a correlation. For instance, studies have shown that mothers from the US are more likely to marry the fathers of their child if those men have higher educational levels (Sassler et al., 2014). Furthermore, a positive association between education and opportunities to marry amongst men has been well-established (Schneider, 2011; Shafer \& James, 2013). Previous research has demonstrated that this positive association may be the result from an increasing relevance of education for marital behavior across cohorts in the second half of the $20^{\text {th }}$ century (Sweeney, 2002). Furthermore, men from European countries with higher educational levels are more likely to enter partnership unions than men with lower education (Kalmijn, 2011). Additionally, recent evidence from Germany suggests that higher educational levels are positively associated with the onset of serious relationships among men of higher ages (50 years and older) (Rapp, 2018).

Regarding employment status, a positive correlation with marital behavior has been demonstrated by previous research. For instance, several studies based on US data have revealed that employed men are more likely to enter marriage compared to non-employed (Sassler \& Goldscheider, 2004; Schneider, 2011; Shafer \& James, 2013; Sweeney, 2002), and compared to part-time employed males (Schneider, 2011; Schneider et al., 2018). Regarding European countries, previous research suggests similar associations. For instance, employed men in European countries are more likely to form a union (Kalmijn, 2011). Furthermore, being unemployed is negatively linked with the onset of a serious partnership among middle-aged (30-50 years) and older men (50+) in Germany (Rapp, 2018). 
Given that LS are positively linked with SES and that SES is positively linked with marital status, as shown above, it seems reasonable to assume a positive association between LS and marital status as well, which in turn may predict higher fertility. This is supported by previous findings suggesting that the role of partnership status for fertility is well understood (Balbo et al. 2013): cohabiting individuals have higher fertility than non-cohabiting individuals (Baizán et al., 2003; Brien et al., 1999; Laplante \& Fostik, 2015), and fertility is higher for married than for cohabiting couples (Baizán et al. 2003; Spéder \& Kapitány 2009).

As the literature review above has shown, indicators of SES are linked with family formation processes such as getting married or cohabiting. However, previous research suggests that the association between SES and partnership formation may vary across ages among men (Rapp, 2018). This may also be the case with respect to fertility outcomes. Therefore, we consider accumulated income, the highest level of education and whether a man has ever been married by age 39 in our study. Following this approach, we control for potential differences by age until our cut-off at 39 years of age by examining completed fertility trajectories including SES indicators measured at higher ages.

\section{Data and Variables}

Data

The present analyses are based on Swedish register data. Swedish residents each have a unique identification number, through which information from different sources can be linked, e.g. information on fertility, mortality or marital behavior. Birth data was taken from administrative registers on fertility. Leadership skills (LS) as our explanatory of interest was measured by the military service between 1983-1997. All young males were obliged to attend military recruitment during that time period. We restrict the analytical sample to men who were 17-20 years of age at time of recruitment, which captures the vast majority of the male population (98\%) from the considered cohorts (1963-1979). Thus, our analytical sample is relatively homogeneous and contains information of 650,947 males who have been registered in Sweden throughout the entire time between military recruitment and most recent available data (2018). Men who emigrated from Sweden or died before age 39 were excluded from the analyses. The age range for measurement of completed fertility in our analytical sample is between 39 and 55 years, depending on birth cohort. This allows us to include as much fertility information as possible, whereas independent variables are either fixed (e.g. family background), measured at military recruitment (LS, cognitive ability), or at exact age 39 (cumulated income, highest education, marital status). The age of 39 years can be considered 
as reasonable age for fertility completion. Although men can still have children after this age, previous research has shown that fertility patterns remain relatively stable after age 40 (Barclay \& Kolk, 2020). Multigenerational registers were used to derive information on full siblings and family background via identification numbers of both mothers and fathers. For the fixed effects approach, only full siblings with same registered mothers and fathers were considered. This allows us to control for unobserved heterogeneity based on genetics, childhood experiences, parental education and other shared background information. Administrative registers provided us with basic socio-demographic information such as marital behavior, and educational level. Cumulative income was calculated based upon tax registers.

The register data allow us to examine the association between personality facets and fertility on the population level whereas previous studies, to the best of our knowledge, only looked at this link based on survey data. However, surveys usually face the problems of selection effects or non-response-bias. Register-based research captures everybody, even individuals who would not be willing or capable (e.g. disadvantaged men) to respond to surveys and therefore, we obtain a clear picture for the entire population instead of just its subsample. This is an important advantage of our data because males with certain characteristics (e.g. low cognitive ability) may be more likely to refuse participation in surveys and remain childless over time, which will result in biased estimates based on survey data. Since we consider (almost) the entire Swedish male population (no matter whether LS were measured or not), the statistical power of our analyses is very high - or in other words, the uncertainty about the associations that we may find is minimized. Furthermore, surveys usually use self-reports on personality. Information from the Swedish military, however, is based on interviews with psychologists even if LS were only collected for males at the top half of the cognitive ability distribution.

\section{Variables}

There are two outcomes of our study. First, we explore the association between leadership skills and number of children (range: $0-22$ ) by age 39 or older. We furthermore examine the relationship between LS and childlessness by age 39 or older.

\section{Leadership skills}

Our main explanatory variable represents the leadership skills (LS) of each young man at time of military enrolment. This information is based on 20-25-minutes interviews by psychologists. The Swedish military provides information about LS on a scale ranging from 1-9. LS are included as a categorical variable ranging from 1 (low skills) to 9 (high skills) in our models, 
and the middle category, i.e. score 5 , serves as reference group. There is an additional " 0 " category. However, category 0 has to be considered with caution since relatively many males belong to this category and it remains unclear how individuals were assigned to this group. We decided to combine score 0 with the group of missing values, and this combination is included as an additional category of the LS variable. Additional analyses have revealed that model estimates are very similar between these two groups (see Fig. A1 and A2).

\section{Cognitive skills}

The Swedish military collected information on leadership skills only for men who scored in the top half of the cognitive skills distribution. Cognitive skills are measured as scale ranging from 1 (low skills) to 9 (high skills), and this information also comes from the military enlistment. Table 1 below provides an overview of the tabulation between LS and cognitive ability scores. It is clear that the vast majority of young men with scores from 1-4 on the cognitive ability scale were not assessed on their LS (99\% and more) and, therefore, received a missing value on LS. It is important to keep in mind that we only look at men with cognitive skills above the median when we examine the association between LS scores (that are non-missing) and fertility.

Table 1: Leadership Skills according to Cognitive Ability

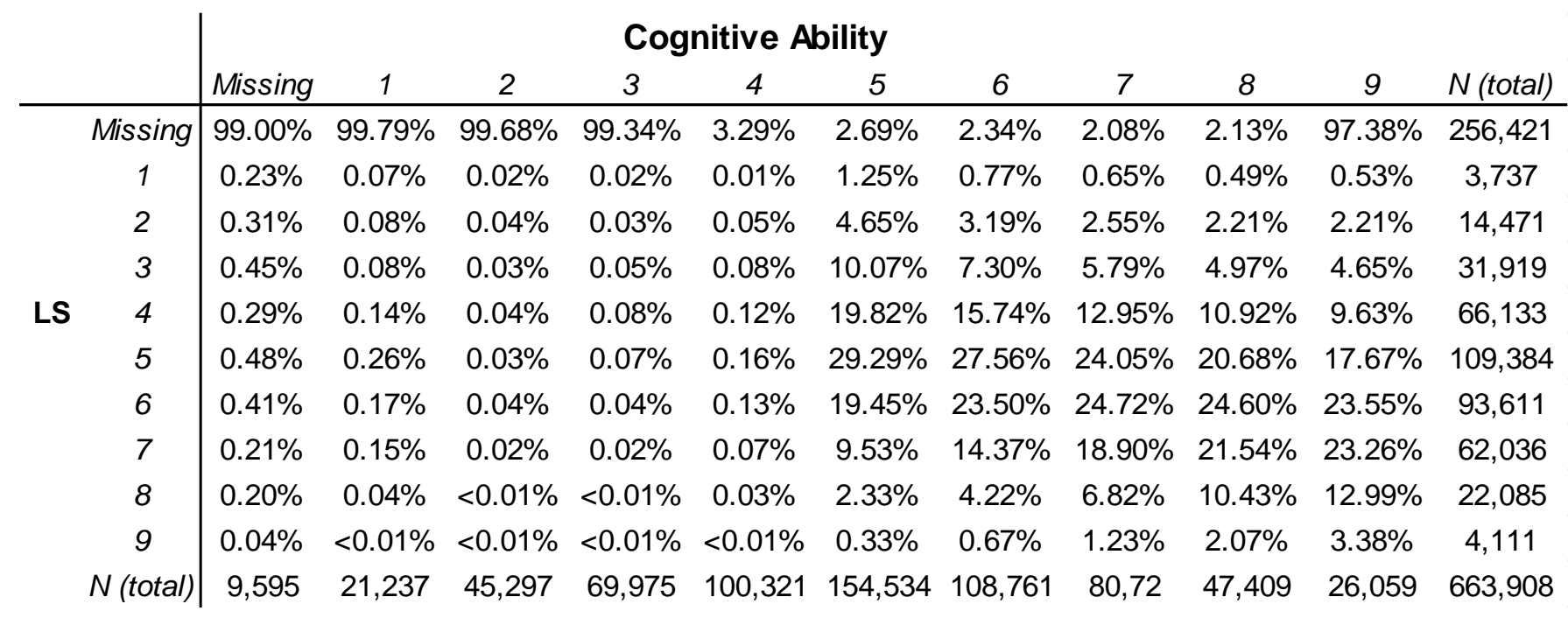




\section{Variation by SES and marital status}

Further characteristics are included in our analyses since previous research suggests strong associations between socio-demographic factors and fertility. We have already discussed the role of income, education, and marital status in terms of fertility outcomes. Furthermore, LS are linked with these mechanisms so that they are of particular interest in our study. The correlation between LS and career outcomes such as income has been shown above, and income is positively associated with fertility in Sweden (Andersson \& Scott, 2007; Kolk, 2019). Therefore, we consider income an important mediator for the LS-fertility link. Since income can vary for individuals over time, we cumulated income for all individuals by age 39 and included the logarithm of it in our models. Additionally, we explore the role of income by two further analytical approaches. First, we ran additional models using income as outcome in order to explore the association between LS and cumulated income. Second, we stratified our main models according to income deciles so that the LS-fertility link is presented for each decile of cumulated income by age 39. Income has been adjusted for inflation in both approaches using data provided by Statistics Sweden (Consumer Price Index, $1980=100$ ).

Furthermore, education - measured as highest educational level obtained by year 2018 ( 1 "No Basic Education", 2 "Primary", 3 "Lower Secondary", 4 "Upper Secondary", 5 "PostSecondary", 6 "Tertiary", 7 "Doctor") - is included as potential mediator in our models. Again, we conducted additional analyses by regressing LS on educational outcomes in later life. For simplification purposes and due to particular interest in the transition to highest education, we used a binary-coded indicator (0 "Lower than Tertiary", 1 "Tertiary and higher"). Additionally, we stratified our main models according to completed educational level, grouped as follows: "Primary or lower"; "Secondary"; and, "Post-Secondary or higher". Civil (relationship) status may also serve as mediator for the LS-fertility link. Consequently, we included marital status as binary coded variable in our models (0 "Never married", 1 "Ever married") and used this variable both as an outcome as well as a stratification factor for our main effects.

\section{Within-family comparison}

Several factors exist that influence both leadership skills and fertility behavior. A number of these factors relate to shared family background information such as parental education, religiosity, and fertility preferences. For instance, previous research has shown that genetics may affect both leadership (De Neve et al., 2013) and fertility behavior (Kohler et al., 1999). Furthermore, it has long been known that fertility patterns between generations are linked, and it has been argued that these correlations may be based on intergenerational transmissions of fertility preferences and attitudes (Anderton et al., 1987; Johnson \& Stokes, 1976). 
Consequently, previous research has developed increasing interest in family factors as determinants of fertility. Potential associations between personality and fertility may disappear when controlling for shared background information within families since siblings may have similar fertility patterns (Buyukkececi \& Leopold, 2021; Dahlberg \& Kolk, 2018; Kolk, 2015; Lyngstad \& Prskawetz, 2010). These shared factors are captured using fixed effects models.

\section{Covariates}

Fertility outcomes are linked with siblings fertility behavior (Buyukkececi \& Leopold, 2021; Kuziemko, 2006; Lyngstad \& Prskawetz, 2010; Murphy, 2013), the presence of siblings (Cools \& Kaldager Hart, 2017; Murphy \& Knudsen, 2002) and birth order (Morosow \& Kolk, 2020). Therefore we control for sibling group size (1-18) and birth order (1-16) in our models. Both indicators were created using full family information, i.e. sisters were involved in counts. Additionally, we include the year of birth (1963-1979) in order to control for potential birth cohort effects.

\section{Statistical Models}

We applied Poisson regression models in order to examine the association between LS and the number of children by age 39 and higher. The models are based on following equation:

$$
\begin{aligned}
& \log \left(E\left[Y_{i} \mid X_{i}\right]\right)=\beta_{0}+\beta_{1} \text { leadership }_{i}+\beta_{2} \text { cognitive }_{i}+\beta_{3} \ln \left(\text { income }_{i}+\beta_{4} \text { education }_{i}+\right. \\
& \beta_{5} \text { married }_{i}+\beta_{6} \text { birth_year }_{i}+\beta_{7} \text { birth_order }_{i}+\beta_{8} \text { sibling_group_size }_{i}+\varepsilon_{i}
\end{aligned}
$$

The outcome of the Poisson regression models is the logarithm of the expected kids count $Y$ for each individual $i$ conditioned on the vector of all independent variables $X_{i}$. The intercept of the model is represented by $\beta$, and $\varepsilon_{i}$ describes the error term that can vary between individuals. The independent variable of main interest is leadership, which is included as categorical variable (scores 1-9) in the models as well as the covariate cognitive (scores 1-5). Income has been cumulated until age 39 and we included the logarithm of it as continuous variable in our models. The covariate education represents the highest educational level of the individual ( 1 - "No basic education" to 7 - "Doctor") and married is the indicator whether the male has ever been married by 2018 ( 0 - Never married, 1 - Ever married). The last set of covariates represents family background information: birth_year is a vector of dummy variables for all birth cohorts in the analytical sample (1963-1979), birth_order stands for the birth order that the individual holds within the family (constructed with information on both full male and 
full female siblings), and sibling_group_size provides information on the total number of brothers and sisters (including the individual itself). The last covariate was excluded in the fixed effects models since these require variation in all explanatories between siblings by definition.

Linear probability models (LPM) were run to explore the link between explanatories and the likelihood to remain childless by age 39 and higher. The LPM of our analyses are based on the following equation:

$\operatorname{Pr}\left(Y_{i}=1 \mid X_{i}=x_{i}\right)=\beta_{0}+\beta_{1}$ leadership $_{i}+\beta_{2}$ cognitive $_{i}+\beta_{3} \ln \left(\right.$ income $_{i}+\beta_{4}$ education $_{i}+$ $\beta_{5}$ married $_{i}+\beta_{6}$ birth_year $_{i}+\beta_{7}$ birth_order $_{i}+\beta_{8}$ sibling_group_size $_{i}+\varepsilon_{i}$

We are interested in the binary coded information whether the individual remained childless by age 39 or higher $(Y=1)$, or not $(Y=0)$. Therefore, the outcome can be considered as probability to remain childless by age 39 or later. The independent variables are the same as shown in equation (1) for the Poisson regression models. Again, sibling group size was excluded for fixed effects approaches.

Furthermore, we applied simple OLS regression models for additional analyses with continuous outcomes (e.g. when the association between LS and logarithm of cumulated income was examined). Compared to equation (2), only the outcome is changed from binary to continuous.

\section{Results}

\section{Descriptives}

Table A1 in the Appendix gives an overview about the variables that we used in our models. The number of children by age 39 or older serves as one of our main fertility outcomes. About one fifth of our study population remains childless by age 39 (20.64\%), and twice as many have two children $(42.82 \%)$. We group the number of children at nine together with higher parities for visualization purposes only here. As outcome in our analyses, this variable is included without an open-ended category, i.e. the highest value of this outcome is 22 , which is observed for one individual. Leadership skills can be considered as being approximately normally distributed with the largest number of males revealing score 5 (16.72\%). However, the largest category contains males who were coded as "Missing" (37.79\%). Further information about the variables from our models can be seen in Table A1.

Additionally, we show mean values of fertility outcomes and of further important factors according to LS scores in Table 2 below. It can be seen from these simple descriptive statistics 
that the number of children increases with LS with a range of 1.34 to 2.10 children. The overall population mean number of children is 1.73 . Furthermore, about $21 \%$ of our analytical sample remains childless by age 39 and higher. This proportion varies across LS scores with lowest LS revealing the highest proportions of childlessness (>30\%). Further information with regards to other relevant characteristics such as education or income can be seen in Table 2 below.

Table 2: Mean Values of Relevant Factors according to Leadership Skills

$\begin{array}{cccccccc}\text { LS } & \text { \# Children } & \text { Childlessness } & \text { Cogn. Ability } & \text { Education } & \text { Income Dec. } & \text { Married } & \mathbf{N} \\ \text { Missing } & 1.67 & 0.23 & 3.19 & 3.44 & 5.00 & 0.44 & 246,020 \\ 1 & 1.34 & 0.38 & 5.81 & 3.92 & 3.67 & 0.34 & 3,694 \\ 2 & 1.36 & 0.35 & 5.89 & 4.09 & 4.31 & 0.38 & 14,361 \\ 3 & 1.48 & 0.31 & 5.91 & 4.11 & 4.78 & 0.41 & 31,742 \\ 4 & 1.61 & 0.25 & 5.95 & 4.19 & 5.28 & 0.46 & 65,847 \\ 5 & 1.75 & 0.19 & 6.06 & 4.40 & 5.73 & 0.52 & 108,856 \\ 6 & 1.85 & 0.15 & 6.33 & 4.74 & 6.18 & 0.58 & 93,002 \\ 7 & 1.95 & 0.12 & 6.62 & 5.03 & 6.63 & 0.63 & 61,554 \\ 8 & 2.03 & 0.10 & 6.99 & 5.27 & 7.06 & 0.68 & 21,823 \\ 9 & 2.10 & 0.09 & 7.23 & 5.38 & 7.35 & 0.72 & 4,048 \\ \text { Average } & 1.73 & 0.21 & 5.08 & 4.14 & 5.52 & 0.50 & 650,947\end{array}$

\section{Main Effects}

Figure 1 shows the LS coefficients from Poisson regression models with number of children by age 39 or later as an outcome for both between- and within-family comparisons. Both models were estimated with and without mediators (income, education, marital status) but always including the other covariates (cognitive ability, birth year, birth order, sibling group size). Figure 1 illustrates that lower scores on LS are negatively associated with the number of children, and higher LS scores are positively linked with offspring count. The results from the fixed effects approach (within-family comparison) do not differ much from the model based on between-family estimation. The pattern can be described as an S-shape since the lowest scores do not differ very much compared to each other and neither do the higher LS scores. The graphs reveal that the mediators (income, education, marital status) can explain the LSfertility link to some extent, in particular with respect to between-family considerations. When mediators are excluded, the curve is steeper and differences according to LS in number of children are relatively large, e.g. males with lowest LS scores have approximately 0.25 fewer children on average compared to males with LS scores of 5 in the between-family comparison. Regarding models that include mediators, the general pattern remains but the magnitudes are smaller. For instance, males with lowest LS scores (1,2 or 3$)$ at time of military recruitment 
have around 0.1 fewer children compared to the reference group (score 5). This represents a reduction in offspring count of ca. 5.8\% compared to the average number of children in the overall population (1.73). The general patterns remain similar but to a slightly lower extent when comparing male siblings to each other (within-family comparison).

Figure 1: The relationship between leadership scores measured at ages 17-20 and total number of children by age 39 or later amongst Swedish men born 1963-1979. Poisson regression models, error bars are $95 \%$ confidence intervals.

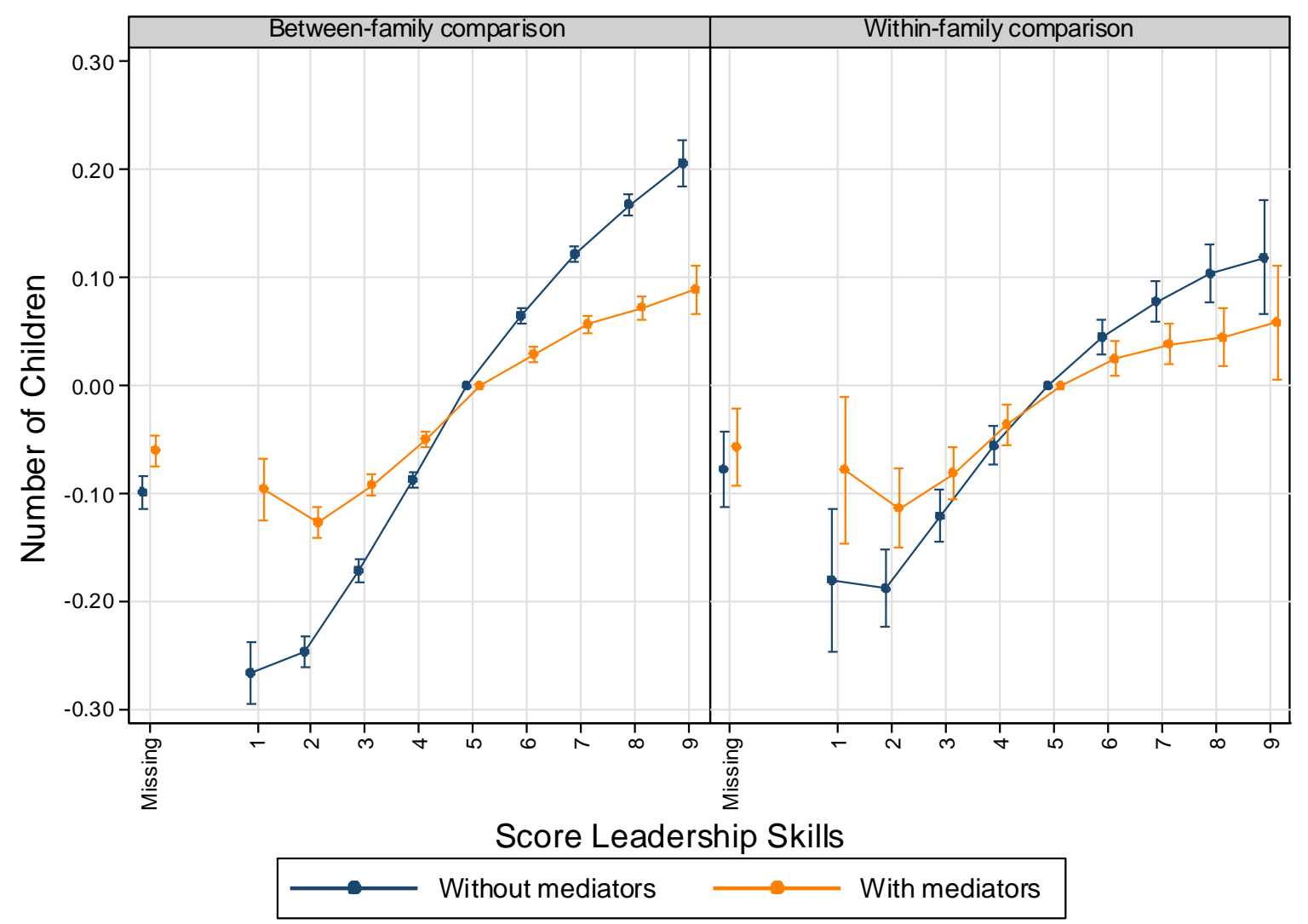

Note: Models without mediators control for cognitive abilities, birth year, birth order, and in case of between-family considerations for sibling group size. Models with mediators include income, education, and marital status additionally.

Figure 2 below depicts the association between LS and the probability of remaining childless by age 39 or later. Again, results are shown for the total sample (between-family analyses) as well as for the sample including brothers only (within-family consideration) separately. Graphs contain estimates from models with and without mediators. In all models, a negative trend can be seen: men with the lowest LS scores are more likely to stay childless by age 39, while higher scores on LS are associated with a lower probability of being childless. The results from models excluding income, education, and marital status show a steeper gradient in the 
relationship between LS and childlessness than models including these variables, in particular in between-family analyses. According to these models, men with the lowest LS scores have almost a $20 \%$ higher probability to remain childless compared to the reference group (LS score of 5). On the other tail, men with the highest LS score have a more than $10 \%$ lower probability of being childless relative to the reference group. This pattern weakens when models control for income, education, and marital status. Nevertheless, men with the lowest LS scores have a coefficient of 0.08 , which means a $38 \%$ higher probability to remain childless compared to the baseline probability (0.21). Again, fixed effects models show similar patterns but on a slightly lower level.

Figure 2: The relationship between leadership scores measured at ages 17-20 and probability to remain childless by age 39 or later amongst Swedish men born 1963-1979. Linear probability models, error bars are $95 \%$ confidence intervals.

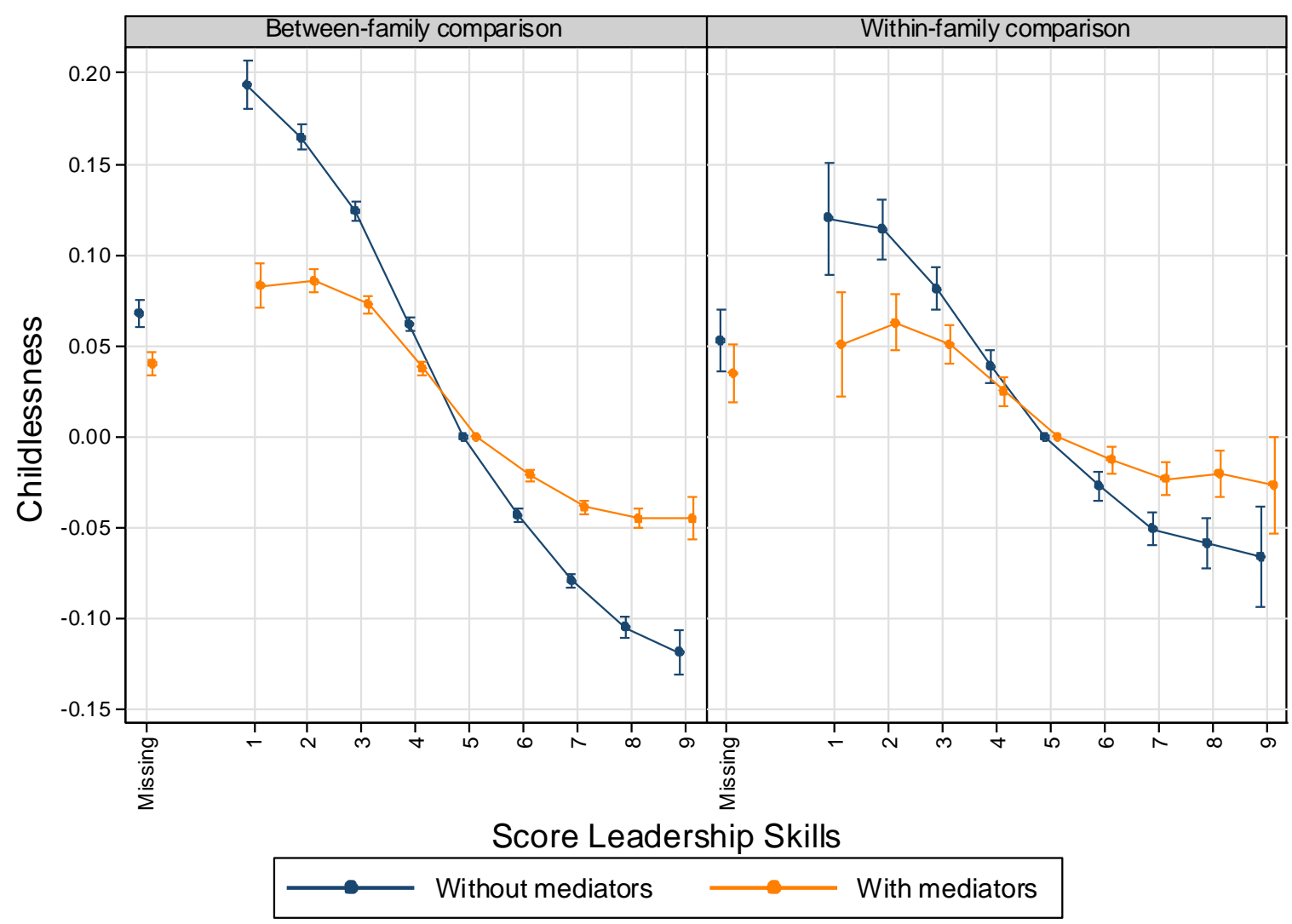

Note: Models without mediators control for cognitive abilities, birth year, birth order, and in case of between-family considerations for sibling group size. Models with mediators include income, education, and marital status additionally. 


\section{The Role of Cognitive Ability}

In order to explore the shown association between LS and completed fertility a bit further we ran models with and without adjustment for cognitive skills. This allows us to estimate the effect that may be explained by cognitive skills, particularly relevant for our analyses since LS were mainly collected for the males on the top half of the cognitive ability distribution. Figures $A 3$ and A4 in the Appendix suggest that cognitive skills do not play a great role in the LS-fertility association. Estimates from both models (with and without cognitive abilities) are very similar, and this can be concluded from both between- and within-family analyses. The only exception from this pattern is the group containing missing values in the between-family considerations.

\section{Leadership Skills and Mediators}

The findings above demonstrate that LS scores are clearly linked with completed fertility among males in Sweden. We aim for possible explanations of this association by examining the relationship between LS and a set of potential mediators that have been found to affect fertility as well. Therefore, we ran linear regression and linear probability models using income, educational level, and marital status as outcomes and LS as an independent variable. Results are shown in the Appendix (Fig. A5-A7). In general, positive associations between LS and income, education as well as the probability of getting married can be seen, i.e. higher LS predict a higher cumulated income, a higher probability of receiving tertiary education, and a higher probability of getting married by age 39 .

In order to examine the role of potential mediators on the LS-fertility link further, we ran additional models including interaction terms between LS and income (as deciles), education (grouped in "Primary or lower", "Secondary", "Post-Secondary", "Missing"), and marital status ("Never married", "Ever married"). Findings are shown in Fig. 3 and 4 below (and Fig. A8, respectively).

Figure 3 refers to the interaction between LS and income in deciles regarding childlessness based upon both between- and within-family models. Whereas males from the lowest income deciles have the highest probabilities of being childless by age 39 or later, men from the highest income groups are less likely to stay childless by this age. But not only the magnitudes are different across income deciles. The coefficients across LS scores also differ within income groups. In general, lower LS scores are linked with higher probabilities, and higher LS are associated with lower probabilities to remain childless. Most distinct patterns can be observed in lower income deciles. Figure A9 in the Appendix shows the corresponding patterns with regards to offspring count. Figures $\mathrm{A} 10$ and $\mathrm{A} 11$ demonstrate the interaction between $\mathrm{LS}$ and 
education as well as between LS and marital status regarding number of children as fertility outcome.

Figure 3: The relationship between leadership scores measured at ages 17-20 and the probability to remain childless by age 39 and higher amongst Swedish men born 1963-1979. Linear probability models by income deciles, error bars are 95\% confidence intervals.

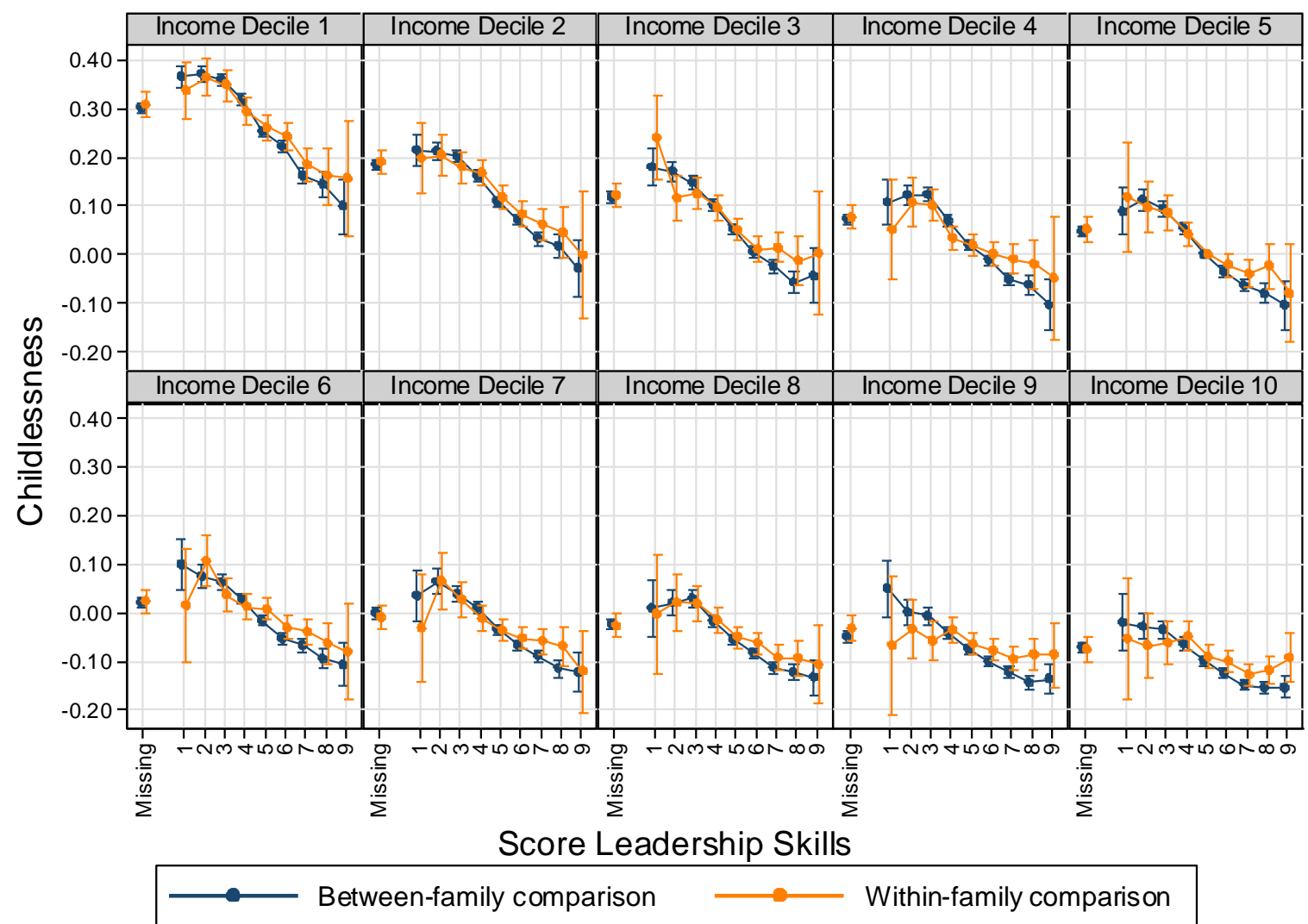

Note: Models control for cognitive ability, birth year, birth order, and in case of between-family considerations for sibling group size.

The association between LS and childlessness by age 39 and higher according to marital status is shown in Figure 4. Estimates of between-family considerations are very similar to the ones of within-family models. Findings for men who ever got married demonstrate that LS does not seem to play a great role with regards to the probability to remain childless. Negative associations between LS and childlessness (coefficients between 0.06 and -0.04) are rather marginal compared to the reference group ( $\mathrm{LS}=5$ ). These correlations are attenuated when controlled for shared factors. With respect to the males who have never been married, there is a clear relationship between LS and fertility. Men with lowest LS scores $(1,2,3)$ show a more than $35 \%$ (within-family) or $40 \%$ (between-family) higher probability to remain childless by age 
39 and higher compared to the reference group (LS score 5, ever married). Highest LS scores $(7,8,9)$ are still positively linked to childlessness but to a smaller extent (coefficients of 0.15 0.2). Findings with respect to offspring counts are shown in Figure A11 in Appendix.

Figure 4: The relationship between leadership scores measured at ages 17-20 and the probability to remain childless by age 39 and higher amongst Swedish men born 1963-1979. Linear probability models by marital status, error bars are 95\% confidence intervals.

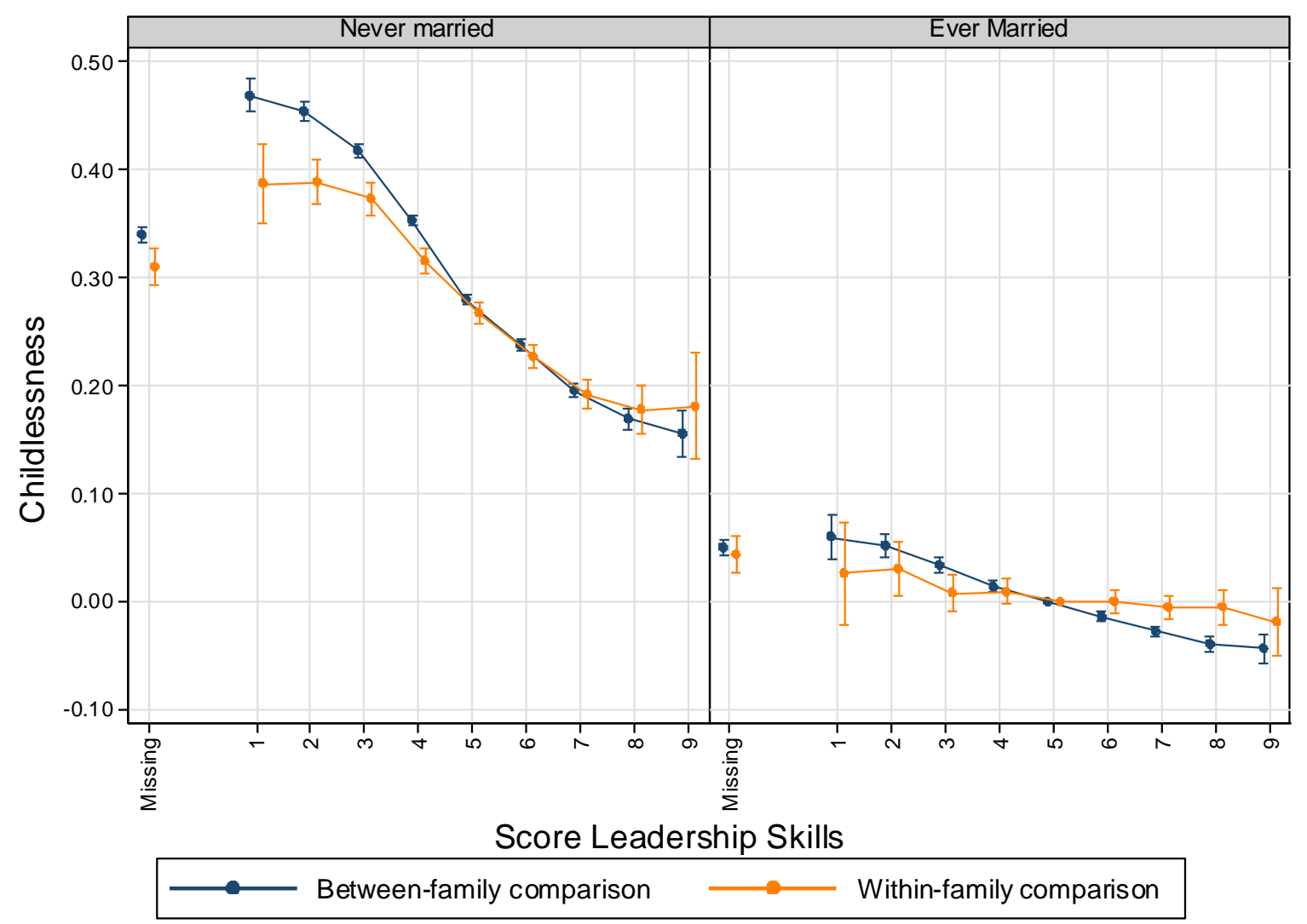

Note: Models control for cognitive ability, birth year, birth order, and in case of between-family considerations for sibling group size.

\section{Discussion}

\section{Conclusions}

It was the aim of our study to disentangle the relationship between leadership skills (LS) and completed fertility among males in Sweden. Swedish register data allowed us to examine the extent to which LS scores (measured at time of military conscription) are linked with number of children and childlessness by age 39 and higher. Findings from Poisson Regression and Linear Probability models have shown that higher LS are linked with a higher offspring count 
and lower levels of childlessness while lower LS are associated with fewer children and higher levels of childlessness by age 39 and higher. Furthermore, our results show associations in (reversed) S-shape patterns, at least in full models including all covariates. Comparisons between within-family (fixed effects approach) and between-family considerations indicate no strong differences in the examined personality-fertility link, indicating that differences in fertility by LS scores are not strongly driven by shared factors such as socioeconomic status or genes linked to the family of origin. However, differences by income decile, educational level and marital status are evident. The association between LS and fertility appears stronger amongst men in lower income deciles, higher education groups and men who have never been married. This indicates important mediating roles of the socio-economic indicators and marital status for the LS-fertility link, in particular considering the strong associations between income, education, and marital status on the one side, and fertility on the other. The mediating role is supported by extra analyses using income, education, and marital status as outcomes depending on LS and other covariates. It is important to interpret these findings cautiously since a large number of males was not assessed regarding their LS. It seems that mainly individuals on the top half of the cognitive skills distribution have been evaluated according to their LS. We addressed this data limitation by treating males with missing values as an additional group rather than excluding them from the analysis. Our analyses including these missing values have shown that this group reveals similar associations with fertility as the males with lower LS scores, which indicates that low cognitive skills are possibly linked with lower LS. Regarding sibling comparisons, we applied fixed effects approaches, from which no essential differences compared to between-family considerations have been detected.

Our study reveals a number of strengths and limitations. One of the most important weaknesses of our analyses is it that we cannot examine the LS-fertility relationship for women in Sweden since information on LS have only been available for men who attended the military recruitment. Additionally, there is evidence that kin effects on own fertility should be considered more cautiously since different relatives (and different ties) might affect individuals' fertility differently. For instance, older brothers may influence women's fertility differently than older sisters do (Sear et al., 2003). Apart from sisters who had to be ignored using Swedish register data, we could not capture other social influences by peer groups (e.g. friends) that may play an important role as well.

The measurement of leadership represents a further limitation of our study. It was based on a rating by psychologists on a leadership skill scale. In this point, we are not entirely sure about the exact evaluation on this facet, i.e. how the leadership skills scores were obtained (e.g. by the subjective assessment of the psychologist, by a set of items, or other approaches). Furthermore, we use a relatively broad measurement of LS that is collected by the Swedish 
military. Therefore, we cannot look at underlined facets of leadership, which do exist according to previous research. Facets such as organizational agility, decision quality, ethics, command skills belong to LS (Floris et al., 2020), as well as acting trustworthy, individual timemanagement, taking initiative in different contexts, the ability to encourage others to act and networking (Boone \& Peborde, 2008). These factors may affect career success differently (Floris et al., 2020), which may also have an impact on social standing and fertility. Additionally, the LS were only measured for males from the top half of the cognitive ability distribution. We cannot be certain that our detected associations are still valid when including men with lower cognitive skills.

Another limitation relates to the reciprocal link between LS and potential mediators. We could examine the association between LS measured at military recruitment and income, education as well as marital status by age 39. This analytical approach is in line with previous research. For instance, personality may predict career development (Silver \& Spilerman, 1990) and occupation indicators such as income, in particular if the personality facets fit to the job demands (Denissen et al., 2018). However, we had to neglect the reverse relationship between mediators and LS since no changes in LS over time have been recorded. Previous research suggests that personality facets may change due to certain life events in younger adulthood, e.g. the first romantic relationship or the transition to work or university (Bleidorn et al., 2018). Additionally, previous research has shown that personality changes may be observed over time, in particular when it is measured by interviews instead of questionnaires (Hopwood \& Bleidorn, 2018). Nevertheless, a benefit from our approach is that LS was measured in early adulthood, and this obviates any concerns about reverse causality driving the association that we observe between LS scores and fertility.

On the other hand, our study reveals a number of strengths. Due to the unique identification number that each individual in Sweden obtains, we could link leadership skills from military service data with a number of socio-demographically relevant factors such as fertility, marital status, or education from other Swedish registers. The power of our data furthermore allowed us to compare male siblings to each other in order to examine whether within-family analyses reveal differences compared to between-family considerations.

Another strength of our study is it to explore the prospective association between leadership skills measured at age of military recruitment (17-20 years) and (almost) completed fertility in mid-adulthood (age 39 and higher). One previous study by Jokela and Keltikangas-Järvinen (2009) reveals a similar study design. However, the sample of the authors was coming from the Cardiovascular Risk in Young Finns Study and, therefore, was much smaller, with about 1,300 participants. Furthermore, the participants in their study were 39 years or younger. 
Contrary, our analyses were based on males who were 39 years and older and, therefore, could be considered as having largely completed fertility.

Register data from Sweden has further advantages over survey data. For instance, surveys usually suffer from selection biases since some individuals may reject participation for various reasons. These individuals may reveal specific patterns with regards to the research interest. In our case, almost all Swedish males from the birth cohorts 1963-1979 have been recorded over most reproductive ages so that we have almost complete fertility information for these cohorts - including individuals who would not participate in a survey. For instance, disadvantaged males may be both more likely to reject survey participation and less likely to get children. These would bias the results in analyses based on survey data. Using Swedish register data, however, overcomes this problem. We must condition our analyses on males with higher cognitive abilities since only these men received a value according to their LS. However, we are aware of these biases whereas researchers do usually not know the reasons of non-participation when using survey data. We could control for cognitive abilities in our models and have not found very large differences compared to models without this factor. Therefore, we would not expect large biases in our findings compared to analyses that include LS for everybody (also males with lower cognitive skills). Conclusions on the population level are more certain than estimates based on survey data. Our estimates have a high degree of precision because we have large statistical power and can draw conclusions more or less directly on the entire population of interest (males in Sweden from birth cohort 1963-1979) instead of drawing a small subsample only.

Although the LS-fertility link could be explored on a population-level based on Swedish register data among males, there is still much room to examine this specific association further. For instance, it would be interesting to explore the leadership-fertility link among women as well since previous research suggests that females reveal different, even stronger, associations with fertility (Jokela \& Keltikangas-Järvinen, 2009). Furthermore, there are more personality facets that may deserve more attention in fertility research. The Swedish Military Enlistment data provide further information on intensity (self-motivation, frequency and intensity of leisure time activities), social maturity (extraversion, social network size, responsibility, independence), emotional stability (ability to manage nervousness and stress), and psychological energy (perseverance, concentration) (Bihagen et al., 2013) that may affect childbearing as well. Additionally, personality may affect other important life outcomes with respect to family formation, e.g. marital behavior. The personality-fertility link may also be explored in other cultural contexts, in particular considering the differences in the association between SES and fertility in the Scandinavian countries on the one hand and other (highincome) countries on the other. 


\section{References}

Amin, V., \& Behrman, J. R. (2014). Do more-schooled women have fewer children and delay childbearing? Evidence from a sample of US twins. Journal of Population Economics, 27(1), 131. https://doi.org/10.1007/s00148-013-0470-z

Andersson, G., \& Scott, K. (2007). Childbearing dynamics of couples in a universalistic welfare state: The role of labor-market status, country of origin, and gender. Demographic Research, 17, 897-938. https://doi.org/10.4054/DemRes.2007.17.30

Anderton, D. L., Tsuya, N. O., Bean, L. L., \& Mineau, G. P. (1987). Intergenerational transmission of relative fertility and life course patterns. Demography, 24(4), 467-480. https://doi.org/10.2307/2061386

Baizán, P., Aassve, A., \& Billari, F. C. (2003). The Interrelations Between Cohabitation, Marriage and First Birth in Germany and Sweden. Population and Environment, 25(6), 531-561. https://doi.org/10.1023/B:POEN.0000039064.65655.3b

Balbo, N., Billari, F. C., \& Mills, M. (2013). Fertility in Advanced Societies: A Review of Research: La fécondité dans les sociétés avancées: un examen des recherches. European Journal of Population / Revue Européenne de Démographie, 29(1), 1-38. https://doi.org/10.1007/s10680-012-9277-y

Bar, M., Hazan, M., Leukhina, O., Weiss, D., \& Zoabi, H. (2018a). Why did rich families increase their fertility? Inequality and marketization of child care. Journal of Economic Growth, 23(4), 427463. https://doi.org/10.1007/s10887-018-9160-8

Bar, M., Hazan, M., Leukhina, O., Weiss, D., \& Zoabi, H. (2018b). Why did rich families increase their fertility? Inequality and marketization of child care. Journal of Economic Growth, 23(4), 427463. https://doi.org/10.1007/s10887-018-9160-8

Barclay, K., \& Kolk, M. (2020). The Influence of Health in Early Adulthood on Male Fertility. Population and Development Review, 46(4), 757-785. https://doi.org/10.1111/padr.12357 
Begall, K. (2013). How do educational and occupational resources relate to the timing of family formation? A couple analysis of the Netherlands. Demographic Research, 29, 907-936. https://doi.org/10.4054/DemRes.2013.29.34

Bernardi, L., \& Klaerner, A. (2014). Social networks and fertility. Demographic Research, 30, 641-670. https://doi.org/10.4054/DemRes.2014.30.22

Bihagen, E., Nermo, M., \& Stern, C. (2013). Class Origin and Elite Position of Men in Business Firms in Sweden, 1993-2007: The Importance of Education, Cognitive Ability, and Personality. European Sociological Review, 29(5), 939-954. https://doi.org/10.1093/esr/jcs070

Bleidorn, W., Hopwood, C. J., \& Lucas, R. E. (2018). Life Events and Personality Trait Change: Life Events and Trait Change. Journal of Personality, 86(1), 83-96. https://doi.org/10.1111/jopy.12286

Boberg-Fazlic, N., Sharp, P., \& Weisdorf, J. (2011). Survival of the richest? Social status, fertility and social mobility in England 1541-1824. European Review of Economic History, 15(3), 365-392. https://doi.org/10.1017/S136149161100013X

Boone, L. W., \& Peborde, M. S. (2008). Developing Leadership Skills in College and Early Career Positions. Review of Business, 28(3), 3-13.

Brien, M. J., Lillard, L. A., \& Waite, L. J. (1999). Interrelated Family-Building Behaviors: Cohabitation, Marriage, and Nonmarital Conception. Demography, 36(4), 535. https://doi.org/10.2307/2648089

Burgess, S., Propper, C., \& Aassve, A. (2003). The role of income in marriage and divorce transitions among young Americans. Journal of Population Economics, 16(3), 455-475. https://doi.org/10.1007/s00148-003-0124-7

Buss, D. M. (1994). The Strategies of Human Mating. American Scientist, 82(3), 238-249.

Buss, D. M. (2006). Strategies of Human Mating. Psychological Topics, 15(2), 239-260. 
Buyukkececi, Z., \& Leopold, T. (2021). Sibling influence on family formation: A study of social interaction effects on fertility, marriage, and divorce. Advances in Life Course Research, 47, 100359. https://doi.org/10.1016/j.alcr.2020.100359

Caucutt, E. M., Guner, N., \& Knowles, J. (2002). Why Do Women Wait? Matching, Wage Inequality, and the Incentives for Fertility Delay. Review of Economic Dynamics, 5(4), 815-855. https://doi.org/10.1006/redy.2002.0190

Chudnovskaya, M. (2019). Trends in Childlessness Among Highly Educated Men in Sweden. European Journalof Population, 35(5), 939-958. https://doi.org/10.1007/s10680-018-9511-3

Clark, G., \& Cummins, N. (2015). Malthus to modernity: Wealth, status, and fertility in England, 15001879. Journal of Population Economics, 28(1), 3-29. https://doi.org/10.1007/s00148-0140509-9

Clark, G., \& Hamilton, G. (2006). Survival of the Richest: The Malthusian Mechanism in Pre-Industrial England. The Journal of Economic History, 66(3), 707-736. https://doi.org/10.1017/S0022050706000301

Clarkberg, M. (1999). The Price of Partnering: The Role of Economic Well-Being in Young Adults' First Union Experiences. Social Forces, 77(3), 945-968.

Cools, S., \& Hart, R. K. (2015). The Effect of Childhood Family Size on Fertility in Adulthood: New Evidence From IV Estimation. Demography, 54(1), 23-44. https://doi.org/10.1007/s13524016-0537-z

Cools, S., \& Kaldager Hart, R. (2017). The Effect of Childhood Family Size on Fertility in Adulthood: New Evidence From IV Estimation. Demography, 54(1), 23-44. https://doi.org/10.1007/s13524-016-0537-z

Cummins, D. (2006). Dominance, Status, and Social Hierarchies. In D. M. Buss (Ed.), The Handbook of Evolutionary Psychology (pp. 676-697). John Wiley \& Sons, Inc. https://doi.org/10.1002/9780470939376.ch23 
Cygan-Rehm, K., \& Maeder, M. (2013). The effect of education on fertility: Evidence from a compulsory schooling reform. LabourEconomics, 25, 35-48. https://doi.org/10.1016/j.labeco.2013.04.015

Dahlberg, J., \& Kolk, M. (2018). Explaining Swedish sibling similarity in fertility: Parental fertility behaviorvs. social background. Demographic Research, 39, 883-896. https://doi.org/10.4054/DemRes.2018.39.32

Damian, R. I., Su, R., Shanahan, M., Trautwein, U., \& Roberts, B. W. (2015). Can personality traits and intelligence compensate for background disadvantage? Predicting status attainment in adulthood. Journal of Personality and Social Psychology, 109(3), 473-489. https://doi.org/10.1037/pspp0000024

De Neve, J.-E., Mikhaylov, S., Dawes, C. T., Christakis, N. A., \& Fowler, J. H. (2013). Born to lead? A twin design and genetic association study of leadership role occupancy. The Leadership Quarterly, 24(1), 45-60. https://doi.org/10.1016/j.leaqua.2012.08.001

Denissen, J. J. A., Bleidorn, W., Hennecke, M., Luhmann, M., Orth, U., Specht, J., \& Zimmermann, J. (2018). Uncovering the Power of Personality to Shape Income. PsychologicalScience, 29(1), 3-13.

Dribe, M., Breschi, M., Gagnon, A., Gauvreau, D., Hanson, H. A., Maloney, T. N., Mazzoni, S., Molitoris, J., Pozzi, L., Smith, K. R., \& Vézina, H. (2017). Socio-economic status and fertility decline: Insights from historical transitions in Europe and North America. Population Studies, 71(1), 3-21. https://doi.org/10.1080/00324728.2016.1253857

Eastwick, P. W., \& Finkel, E. J. (2008). Sex differences in mate preferences revisited: Do people know what they initially desire in a romantic partner? Journal of Personality and Social Psychology, 94(2), 245-264. https://doi.org/10.1037/0022-3514.94.2.245

Fieder, M., Huber, S., Bookstein, F. L., Iber, K., Schafer, K., Winckler, G., \& Wallner, B. (2005). Status and Reproduction in Humans: New Evidence for the Validity of Evolutionary Explanations on 
Basis of a University Sample. Ethology, 111(10), 940-950. https://doi.org/10.1111/j.14390310.2005.01129.x

Floris, M., Wiblen, S. L., \& Anichenko, E. (2020). Senior Project Leadership Skills and Career Stallers: Analysis of Perception Differences and Implications for Careers. Project Management Journal, 51(2), 214-234. https://doi.org/10.1177/8756972820907491

Gray, E., \& Evans, A. (2019). Changing education, changing fertility: A decomposition of completed fertility in Australia. Australian Population Studies, 3(2), 1-15.

https://doi.org/10.37970/aps.v3i2.42

Hart, R. K., \& Cools, S. (2019). Identifying interaction effects using random fertility shocks. Demographic Research, 40, 261-278. https://doi.org/10.4054/DemRes.2019.40.10 Hopcroft, R. L. (2006). Sex, status, and reproductive success in the contemporary United States. Evolution and Human Behavior, 27(2), 104-120. https://doi.org/10.1016/j.evolhumbehav.2005.07.004 Hopcroft, R. L. (2015). Sex differences in the relationship between status and number of offspring in the contemporary U.S. Evolution and Human Behavior, 36(2), 146-151. https://doi.org/10.1016/j.evolhumbehav.2014.10.003 Hopwood, C. J., \& Bleidorn, W. (2018). Stability and change in personality and personal ity disorders. Current Opinion in Psychology, 21, 6-10. https://doi.org/10.1016/j.copsyc.2017.08.034 Horishna, N., Slozanska, H., Soroka, O., \& Romanovska, L. (2019). Exploring the Leadership Skills of Pre-Service Social Work Students: Implications for Social Work Education. Problems of Education in the 21st Century, 77(5), 598-615. https://doi.org/10.33225/pec/19.77.598 Hutteman, R., Bleidorn, W., Penke, L., \& Denissen, J. J. A. (2013). It Takes Two: A Longitudinal Dyadic Study on Predictors of Fertility Outcomes: Dyadic Predictors of Fertility Outcomes. Journal of Personality, 81(5), 487-498. https://doi.org/10.1111/jopy.12006

Impicciatore, R., \& Tomatis, F. (2020). The nexus between education and fertility in six European countries. Genus, 76(1), 1-20. https://doi.org/10.1186/s41118-020-00104-4 
Jalovaara, M., \& Fasang, A. E. (2020). Family Life Courses, Gender, and Mid-Life Earnings. European Sociological Review, 36(2), 159-178. https://doi.org/10.1093/esr/jcz057

Jalovaara, M., Neyer, G., Andersson, G., Dahl berg, J., Dommermuth, L., Fallesen, P., \& Lappegård, T. (2019). Education, Gender, and Cohort Fertility in the Nordic Countries. European Journal of Population, 35(3), 563-586. https://doi.org/10.1007/s10680-018-9492-2

Johnson, N.E., \& Stokes, C. S. (1976). Family size in successivegenerations: The effects of birth order, intergenerational change in lifestyle, and familial satisfaction. Demography, 13(2), 175-187. https://doi.org/10.2307/2060799

Jokela, M. (2012). Birth-Cohort Effects in the Association Between Personality and Fertility. PsychologicalScience, 23(8), 835-841. https://doi.org/10.1177/0956797612439067 Jokela, M., Alvergne, A., Pollet, T. V., \& Lummaa, V. (2011). Reproductive behavior and personality traits of the Five Factor Model. European Journal of Personality, 25(6), 487-500. https://doi.org/10.1002/per.822

Jokela, M., \& Keltikangas-Järvinen, L. (2009). Adolescent Leadership and Adulthood Fertility: Revisiting the "Central Theoretical Problem of Human Sociobiology." Journal of Personality, 77(1), 213-230. https://doi.org/10.1111/j.1467-6494.2008.00543.x

Jones, L., \& Tertilt, M. (2006). An Economic History of Fertility in the U.S.: 1826-1960 (No. w12796; p. w12796). National Bureau of Economic Research. https://doi.org/10.3386/w12796 Kalmijn, M. (2011). The Influence of Men's Income and Employment on Marriage and Cohabitation: Testing Oppenheimer's Theory in Europe. European Journalof Population / Revue Européenne de Démographie, 27(3), 269-293. https://doi.org/10.1007/s10680-011-9238-x Kanazawa, S. (2003). Can Evolutionary Psychology Explain Reproductive Behavior in the Contemporary United States? The Sociological Quarterly, 44(2), 291-302. https://doi.org/10.1111/j.1533-8525.2003.tb00559.x 
Kaufman, G., \& Bernhardt, E. (2012). His and Her Job: What Matters Most for Fertility Plans and Actual Childbearing? Family Relations, 61(4), 686-697. https://doi.org/10.1111/j.17413729.2012.00720.x

Kohler, H.-P., Rodgers, J. L., \& Christensen, K. (1999). Is Fertility Behavior in Our Genes? Findings from a Danish Twin Study. Population and Development Review, 25(2), 253-288. https://doi.org/10.1111/j.1728-4457.1999.00253.x

Kolk, M. (2015). The causal effect of an additional sibling on completed fertility: An estimation of intergenerational fertility correlations by looking at siblings of twins. Demographic Research, 32, 1409-1420. https://doi.org/10.4054/DemRes.2015.32.51

Kolk, M. (2019). The relationship between lifecourse accu mulated income and childbearing of Swedish men and women born 1940-1970. Stockholm Research Reports in Demography, 19, $1-31$.

Kolk, M., \& Barclay, K. (2021). Do income and marriage mediate the relationship between cognitive ability and fertility? Data from Swedish taxation and conscriptions registers for men born 1951-1967. Intelligence, 84, 1-11. https://doi.org/10.1016/j.intell.2020.101514

Kragt, D., \& Day, D. V. (2020). Predicting Leadership Competency Development and Promotion Among High-Potential Executives: The Role of Leader Identity. Frontiers in Psychology, 11, 116. https://doi.org/10.3389/fpsyg. 2020.01816

Kuhn, P., \& Weinberger, C. (2005). Leadership Skills and Wages. Journal of Labor Economics, 23(3), 395-436. https://doi.org/10.1086/430282

Kuo, J. C.-L., \& Raley, R. K. (2016). Is It All About Money? Work Characteristics and Women's and Men's Marriage Formation in Early Adulthood. Journal of Family Issues, 37(8), 1046-1073. https://doi.org/10.1177/0192513X14530973

Kuziemko, I. (2006). Is Having Babies Contagious? Estimating Fertility Peer Effects Between Siblings. Unpublished Manuscript, New Jersey, 1-36. 
Laplante, B., \& Fostik, A. L. (2015). Two period measures for comparing the fertility of marriage and cohabitation. Demographic Research, 32, 421-442. https://doi.org/10.4054/DemRes.2015.32.14

Leikas, S., \& Salmela-Aro, K. (2015). Personality Trait Changes Among Young Finns: The Role of Life Events and Transitions: Personality Change and Life Events. Journal of Personality, 83(1), 117-126. https://doi.org/10.1111/jopy.12088

Liefbroer, A. C. (2005). The Impact of Perceived Costs and Rewards of Childbearing on Entry into Parenthood: Evidence from a Panel Study. European Journal of Population/Revue Européenne de Démographie, 21(4), 367-391. https://doi.org/10.1007/s10680-005-2610-y Liefbroer, A. C., \& Corijn, M. (1999). Who, What, Where, and When? Specifying the Impact of Educational Attainment and Labour Force Participation on Family Formation. European Journalof Population, 15, 45-75.

Low, B. S. (1990). Occupational Status, Landownership, and Reproductive Behavior in 19th-Century Sweden: Tuna Parish. American Anthropologist, 92(2), 457-468.

Lund, O. C. H., Tamnes, C. K., Moestue, C., Buss, D. M., \& Voll rath, M. (2007). Tactics of hierarchy negotiation. Journal of Research in Personality, 41(1), 25-44. https://doi.org/10.1016/j.jrp.2006.01.002

Lyngstad, T. H., \& Prskawetz, A. (2010). Do siblings' fertility decisions influence each other? Demography, 47(4), 923-934. https://doi.org/10.1007/BF03213733

Maurer, T. J., Hartnell, C. A., \& Lippstreu, M. (2017). A model of leadership motivations, error management culture, leadership capacity, and career success. Journal of Occupational and Organizational Psychology, 90(4), 481-507. https://doi.org/10.1111/joop.12181

McAllister, L. S., Pepper, G. V., Virgo, S., \& Coall, D. A. (2016). The evolved psychological mechanisms of fertility motivation: Hunting for causation in a sea of correlation. Philosophical Transactions of the Royal Society B: Biological Sciences, 371(1692), 20150151. https://doi.org/10.1098/rstb.2015.0151 
McClendon, D., Kuo, J. C.-L., \& Raley, R. K. (2014). Opportunities to Meet: Occupational Education and Marriage Formation in Young Adulthood. Demography, 51(4), 1319-1344. https://doi.org/10.1007/s13524-014-0313-x

McCrae, R. R., \& Costa, P. T. (1987). Validation of the Five-Factor Model of Personality Across Instruments and Observers. Journal of Personality and Social Psychology, 52(1), 81-90.

Meyer, J., Fleckenstein, J., Retelsdorf, J., \& Köller, O. (2019). The relationship of personalitytraits and different measures of domain-specific achievement in upper secondary education. Learning and Individual Differences, 69, 45-59. https://doi.org/10.1016/j.lindif.2018.11.005

Monstad, K., Propper, C., \& Salvanes, K. G. (2008). Education and Fertility: Evidence from a Natural Experiment*. Scandinavian Journal of Economics, 110(4), 827-852. https://doi.org/10.1111/j.1467-9442.2008.00563.x

Morosow, K., \& Kolk, M. (2020). How Does Birth Order and Number of Siblings Affect Fertility? A Within-Family Comparison Using Swedish Register Data. European Journal of Population, 36(2), 197-233. https://doi.org/10.1007/s10680-019-09525-0

Mumford, M. D., Marks, M. A., Connelly, M. S., Zaccaro, S. J., \& Reiter-Palmon, R. (2000). DEVELOPMENT OF LEADERSHIP SKILLS: EXPERIENCE AND TIMING. Leadership Quarterly, 11(1), 87-114.

Murphy, M. (2013). Cross-National Patterns of Intergenerational Continuities in Childbearing in Developed Countries. Biodemography and Social Biology, 59(2), 101-126. https://doi.org/10.1080/19485565.2013.833779

Murphy, M., \& Knudsen, L. B. (2002). The intergenerational transmission of fertility in contemporary Denmark: The effects of number of siblings (full and half), birth order, and whether male or female. Population Studies, 56(3), 235-248. https://doi.org/10.1080/00324720215937

Nettle, D., \& Pollet, T. V. (2008). Natural Selection on Male Wealth in Humans. The American Naturalist, 172(5), 658-666. https://doi.org/10.1086/591690 
Neyer, F. J., \& Asendorpf, J. B. (2001a). Personality-relationship transaction in young adulthood. Journal of Personality and Social Psychology, 81(6), 1190-1204. https://doi.org/10.1037/0022-3514.81.6.1190

Neyer, F. J., \& Asendorpf, J. B. (2001b). Personality-relationship transaction in young adulthood. Journalof Personality and Social Psychology, 81(6), 1190-1204. https://doi.org/10.1037//0022-3514.81.6.1190

Pérusse, D. (1993). Cultural and reproductive success in industrial societies: Testing the rel ationship at the proximate and ultimate levels. Behavioral and Brain Sciences, 16(2), 267-283. https://doi.org/10.1017/S0140525X00029939

Pinquart, M., Stotzka, M., \& Silbereisen, R. K. (2008). Personal ity and ambivalence in decisions about becoming parents. Social Behavior and Personality: An International Journal, 36(1), 87-96.

Rapp, I. (2018). Partnership Formation in Young and Older Age. Journal of Family Issues, 39(13), 3363-3390. https://doi.org/10.1177/0192513X18783469

Sassler, S., \& Goldscheider, F. (2004). Revisiting Jane Austen's Theory of Marriage Timing: Changes in Union Formation among American Men in the Late 20th Century. Journal of Family Issues, 25(2), 139-166. https://doi.org/10.1177/0192513X03257708

Sassler, S., \& Lichter, D. T. (2020). Cohabitation and Marriage: Complexityand Diversity in UnionFormation Patterns. Journal of Marriage and Family, 82(1), 35-61. https://doi.org/10.1111/jomf.12617

Sassler, S., Roy, S., \& Stasny, E. (2014). Men's economic status and marital transitions of fragile families. Demographic Research, 30, 71-110. https://doi.org/10.4054/DemRes.2014.30.3

Schneider, D. (2011). Wealth and the Marital Divide. American Journalof Sociology, 117(2), 627-667. https://doi.org/10.1086/661594

Schneider, D., Harknett, K., \& Stimpson, M. (2018). What Explains the Decline in First Marriage in the United States? Evidence from the Panel Study of Income Dynamics, 1969 to 2013. Journalof Marriage and Family, 80(4), 791-811. https://doi.org/10.1111/jomf.12481 
Sear, R., Mace, R., \& McGregor, I. A. (2003). The effects of kin on female fertility in rural Gambia. Evolution and Human Behavior, 24(1), 25-42. https://doi.org/10.1016/S10905138(02)00105-8

Shafer, K., \& James, S. L. (2013). Gender and SocioeconomicStatus Differences in First and Second Marriage Formation: Comparing First and Second Marriage Formation. Journal of Marriage and Family, 75(3), 544-564. https://doi.org/10.1111/jomf.12024

Silver, C. B., \& Spilerman, S. (1990). Psychoanalytic Perspectives on Occupational Choice and Attainment. Research in SocialStratification and Mobility, 9, 181-214.

Skirbekk, V. (2008). Fertility trends by social status. Demographic Research, 18, 145-180. https://doi.org/10.4054/DemRes.2008.18.5

Skirbekk, V., \& Blekesaune, M. (2014). Personality Traits Increasingly Important for Male Fertility: Evidence from Norway. European Journal of Personality, 28, 521-529. https://doi.org/10.1002/per.1936

Sobotka, T., Beaujouan, É., \& Van Bavel, J. (2017). Introduction: Education and fertility in low-fertility settings. Vienna Yearbook of Population Research , 15, 1-16. https://doi.org/10.1553/populationyearbook2017s001

Sodermans, A. K., Corijn, M., Vanassche, S., \& Matthijs, K. (2017). Effects of personality on postdivorce partnership trajectories. Journal of Social and Personal Relationships, 34(7), 1031-1052. https://doi.org/10.1177/0265407516665250

Specht, J., Egloff, B., \& Schmukle, S. C. (2011). Stability and change of personality across the life course: The impact of age and major life events on mean-level and rank-order stability of the Big Five. Journal of Personality and Social Psychology, 101(4), 862-882. https://doi.org/10.1037/a0024950

Spéder, Z., \& Kapitány, B. (2009). How are Time-Dependent Childbearing Intentions Realized? Realization, Postponement, Abandonment, Bringing Forward: Les intentions de fécondité sont-elles réalisées dans le délai prévu ? Réalisation, report, abandon, avancement. European 
Journal of Population / Revue Européenne de Démographie, 25(4), 503-523.

https://doi.org/10.1007/s10680-009-9189-7

Stone, C. B., Lengnick-Hall, M., \& Muldoon, J. (2018). Do Stereotypes of Veterans Affect Chances of Employment? The Psychologist-Manager Journal, 21(1), 1-33.

Stulp, G., Sear, R., Schaffnit, S. B., Mills, M. C., \& Barrett, L. (2016). The Reproductive Ecology of Industrial Societies, Part II: The Association between Wealth and Fertility. Human Nature, 27(4), 445-470. https://doi.org/10.1007/s12110-016-9272-9

Sutin, A. R., Luchetti, M., Stephan, Y., Robins, R. W., \& Terracciano, A. (2017). Parental educational attainment and adult offspring personality: An intergenerational life span approach to the origin of adult personality traits. Journal of Personality and Social Psychology, 113(1), 144166. https://doi.org/10.1037/pspp0000137

Sweeney, M. M. (2002). Two Decades of Family Change: The Shifting Economic Foundations of Marriage. American Sociological Review, 67(1), 132. https://doi.org/10.2307/3088937

Tavares, L. P. (2016). Who Delays Childbearing? The Associations Between Time to First Birth, Personality Traits and Education. European Journal of Population, 32(4), 575-597. https://doi.org/10.1007/s10680-016-9393-1

Tropf, F. C., \& Mandemakers, J. J. (2017). Is the Association Between Education and Fertility Postponement Causal? The Role of Family Background Factors. Demography, 54(1), 71-91. https://doi.org/10.1007/s13524-016-0531-5

Uher, J. (2017). Open Peer Commentary and Authors' Response: Comments. European Journal of Personality, 31(5), 529-595. https://doi.org/10.1002/per.2128

van Wijk, D. C., de Valk, H. A. G., \& Liefbroer, A. C. (2021). Temporary Employment and Family Formation: An Income or Insecurity Effect? European Sociological Review, 37(4), 641-658. https://doi.org/10.1093/esr/jcab007

Vikat, A. (2004). Women's Labor Force Attachment and Childbearing in Finland. Demographic Research, Special 3, 177-212. https://doi.org/10.4054/DemRes.2004.S3.8 
Appendix 
Table A1: Descriptive Statistics - Variables

\# Children

$\begin{array}{lcc}0 & 134,361 & 20.64 \\ 1 & 96,014 & 14.75 \\ 2 & 278,713 & 42.82 \\ 3 & 108,731 & 16.70 \\ 4 & 24,729 & 3.80 \\ 5 & 5,867 & 0.90 \\ 6 & 1,651 & 0.25 \\ 7 & 485 & 0.07 \\ 8 & 204 & 0.03 \\ 9 \text { or more } & 192 & 0.03\end{array}$

Leadership Skills

$\begin{array}{lcc}1 & 3,694 & 0.57 \\ 2 & 14,361 & 2.21 \\ 3 & 31,742 & 4.88 \\ 4 & 65,847 & 10.12 \\ 5 & 108,856 & 16.72 \\ 6 & 93,002 & 14.29 \\ 7 & 61,554 & 9.46 \\ 8 & 21,823 & 3.35 \\ 9 & 4,048 & 0.62 \\ \text { Missing } & 246,020 & 37.79\end{array}$

Cognitive Skills

$\begin{array}{ccc}1 & 21,075 & 3.24 \\ 2 & 45,120 & 6.93 \\ 3 & 69,711 & 10.71 \\ 4 & 99,927 & 15.35 \\ 5 & 153,888 & 23.64 \\ 6 & 108,214 & 16.62 \\ 7 & 80,170 & 12.32 \\ 8 & 47,044 & 7.23 \\ 9 & 25,798 & 3.96\end{array}$

Educational Level

$\begin{array}{lcc}\text { No Basic Education } & 693 & 0.11 \\ \text { Primary } & 53,385 & 8.20 \\ \text { Lower Secondary } & 202,987 & 31.18 \\ \text { Upper Secondary } & 148,774 & 22.86 \\ \text { Post-Secondary } & 98,429 & 15.12 \\ \text { Tertiary } & 137,782 & 21.17 \\ \text { Doctor } & 8,897 & 1.37\end{array}$


Table A1: Descriptive Statistics - Variables (cont.)

Birth Order

$\begin{array}{lcc}1 & 339,335 & 52.13 \\ 2 & 218,315 & 33.54 \\ 3 & 67,671 & 10.40 \\ 4 & 17,180 & 2.64 \\ 5 & 5,077 & 0.78 \\ 6 & 1,926 & 0.30 \\ 7 & 790 & 0.12 \\ 8 \text { or higher } & 350 & 0.05 \\ & 303 & 0.05\end{array}$

Sibling Group Size

$\begin{array}{lcc}1 & 126,364 & 19.41 \\ 2 & 305,005 & 46.86 \\ 3 & 155,918 & 23.95 \\ 4 & 43,426 & 6.67 \\ 5 & 12,239 & 1.88 \\ 6 & 4,396 & 0.68 \\ 7 & 1,863 & 0.29 \\ 8 \text { or more } & 1,736 & 0.27\end{array}$

Civil Status

$\begin{array}{lccccc} & \text { Never Married } & 325,977 & 50.08 & & \\ & \text { Ever Married } & 324,970 & 49.92 & & \\ & & & & & \\ & \text { Observations } & \text { Mean } & \text { Std.dev. } & \text { Min } & \text { Max } \\ \text { Income by age 39 } & 650,947 & 132.62 & 110.20 & -2,409.68 & 46,742.79 \\ \text { Birth Year } & 650,947 & 1971.24 & 4.11 & 1963 & 1979\end{array}$


Figure A1: The relationship between leadership scores (including 0) measured at ages 17-20 and total number of children by age 39 or later amongst Swedish men born 1963-1979. Poisson regression models, error bars are 95\% confidence intervals.

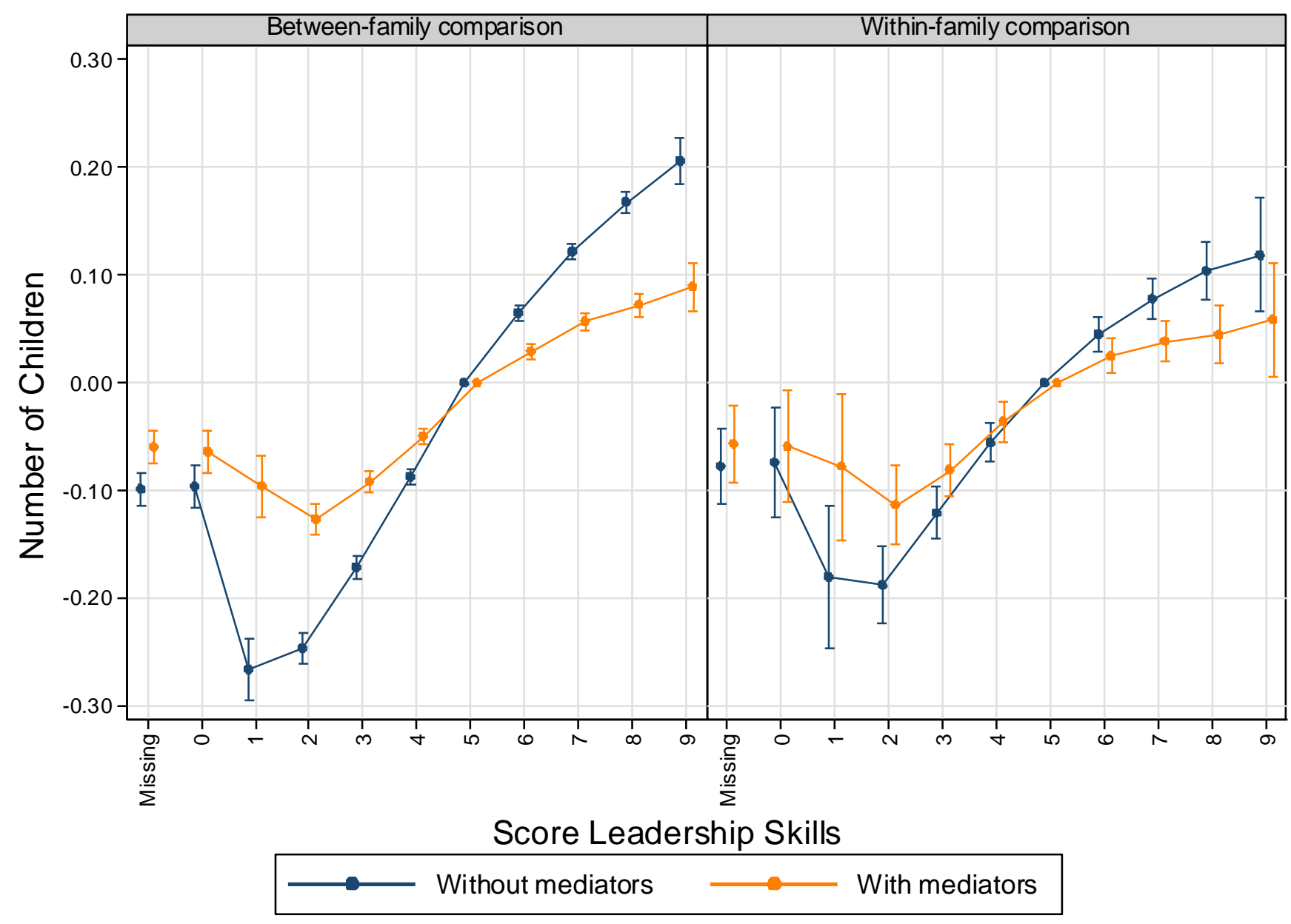

Note: Models without mediators control for cognitive abilities, birth year, birth order, and in case of between-family considerations for sibling group size. Models with mediators include income, education, and marital status additionally. 
Figure A2: The relationship between leadership scores (including 0) measured at ages 17-20 and probability to remain childless by age 39 or later amongst Swedish men born 1963-1979. Linear probability models, error bars are $95 \%$ confidence intervals.

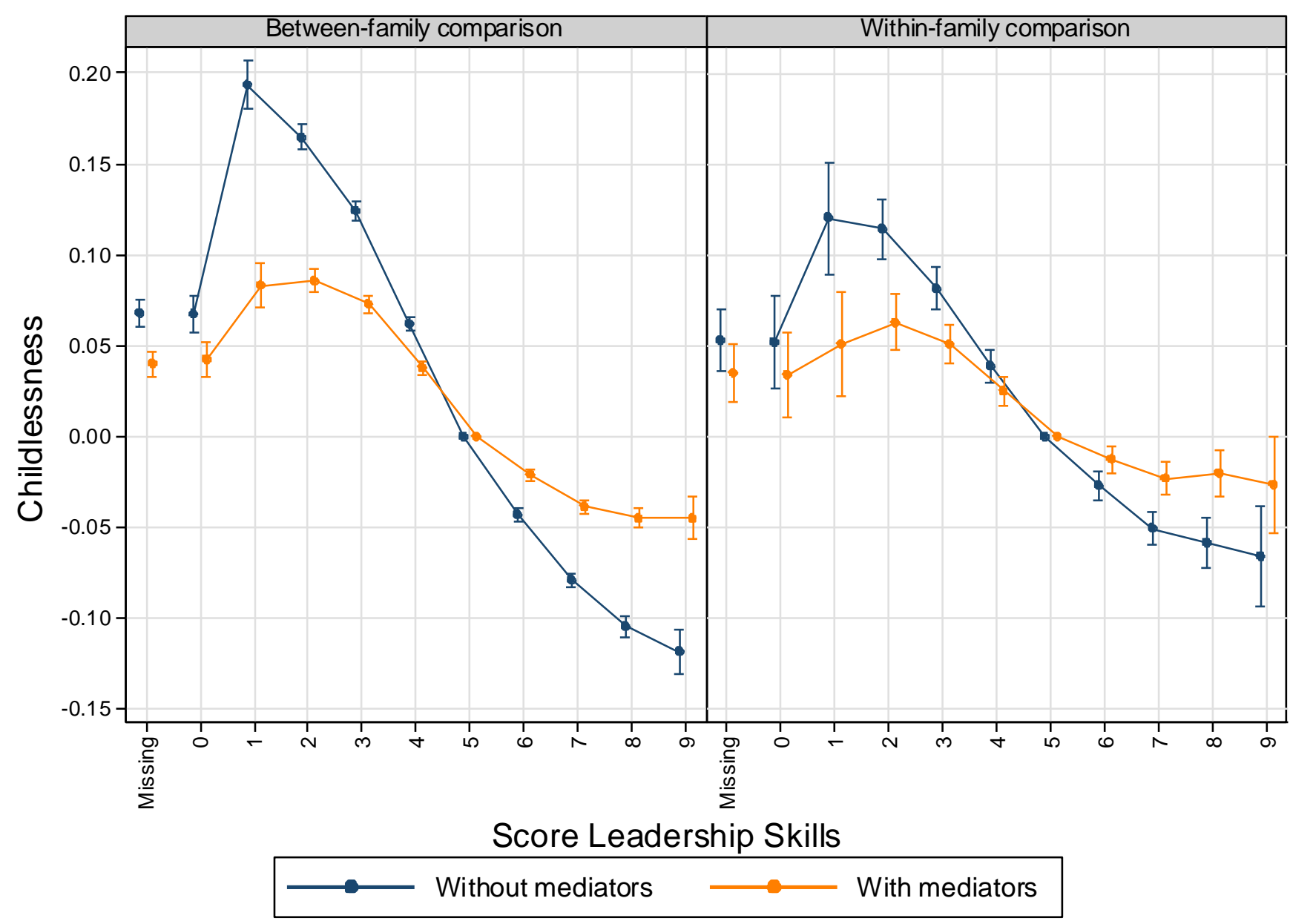

Note: Models without mediators control for cognitive abilities, birth year, birth order, and in case of between-family considerations for sibling group size. Models with mediators include income, education, and marital status additionally. 
Figure A3: The relationship between leadership scores measured at ages 17-20 and total number of children by age 39 or later amongst Swedish men born 1963-1979 (the role of cognitive ability).

Poisson regression models, error bars are 95\% confidence intervals.

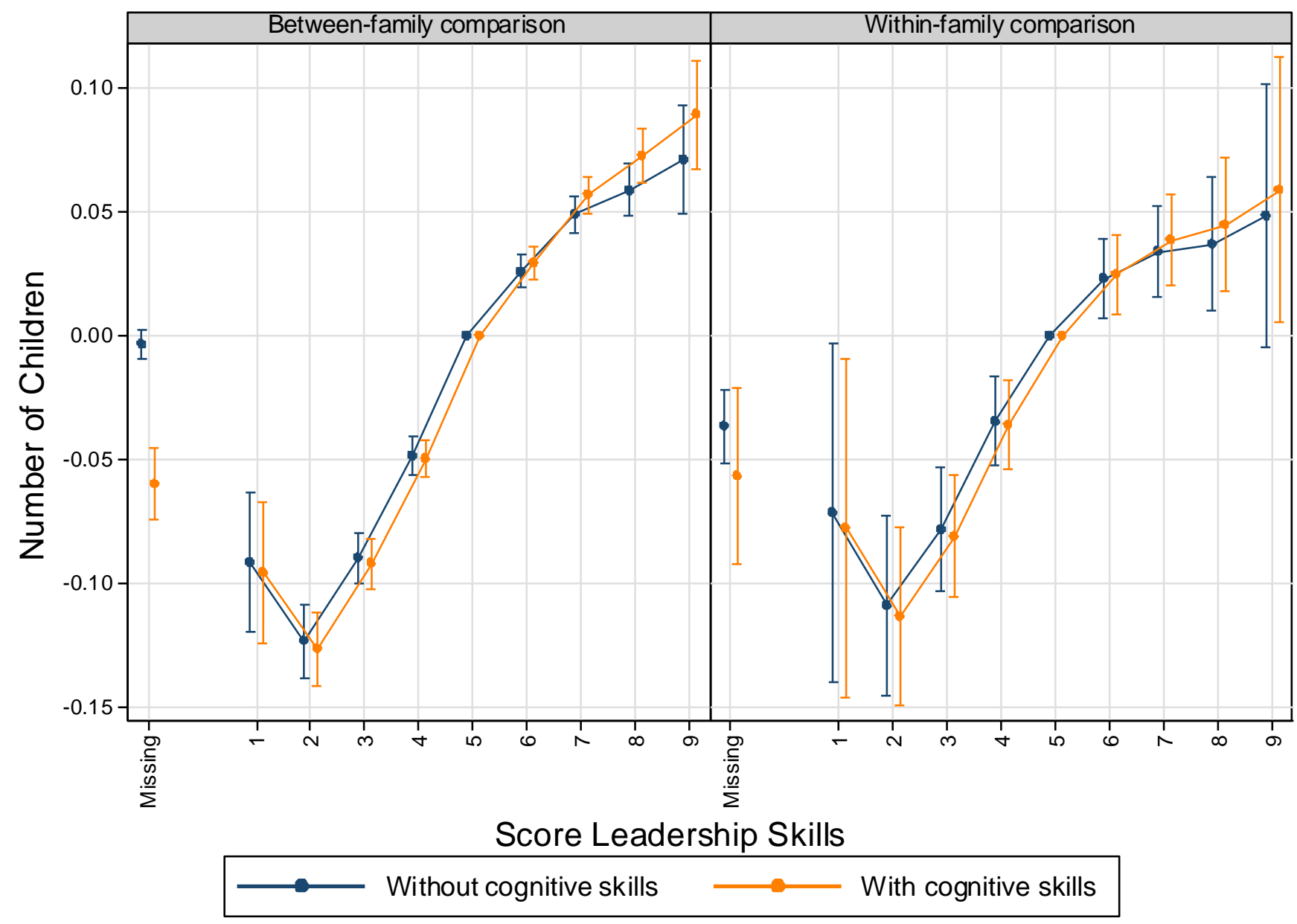

Note: Models without cognitive skills control for income, education, marital status, birth year, birth order, and in case of between-family considerations for sibling group size. Models with cognitive skills include cognitive abilities additionally. 
Figure A2: The relationship between leadership scores measured at ages 17-20 and probability to remain childless by age 39 or later amongst Swedish men born 1963-1979 (the role of cognitive ability). Linear probability models, error bars are $95 \%$ confidence intervals.

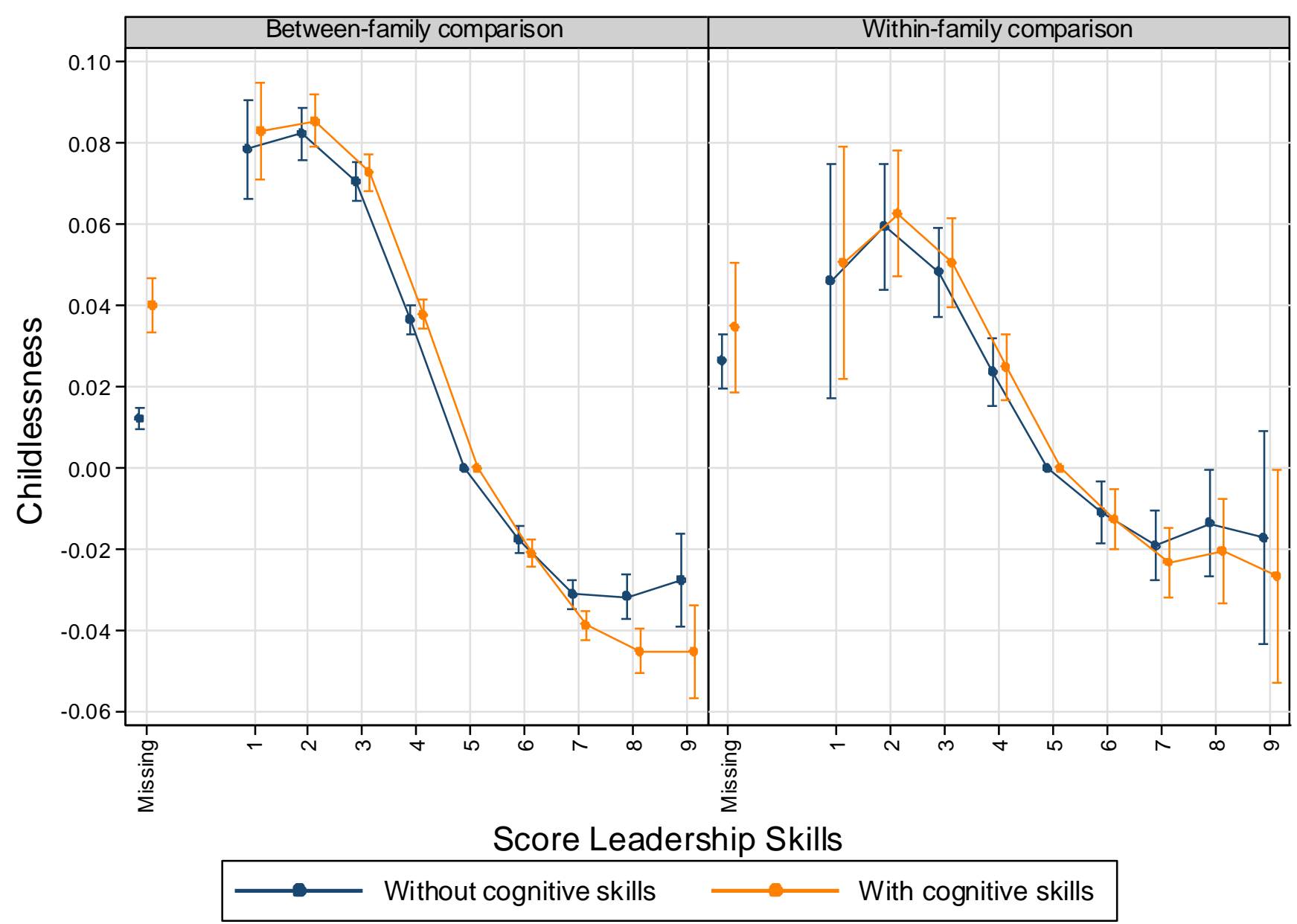

Note: Models without cognitive skills control for income, education, marital status, birth year, birth order, and in case of between-family considerations for sibling group size. Models with cognitive skills include cognitive abilities additionally. 
Figure A5: The relationship between leadership scores measured at ages 17-20 and cumulated income by age 39 amongst Swedish men born 1963-1979. Linear regression models, error bars are 95\% confidence intervals.

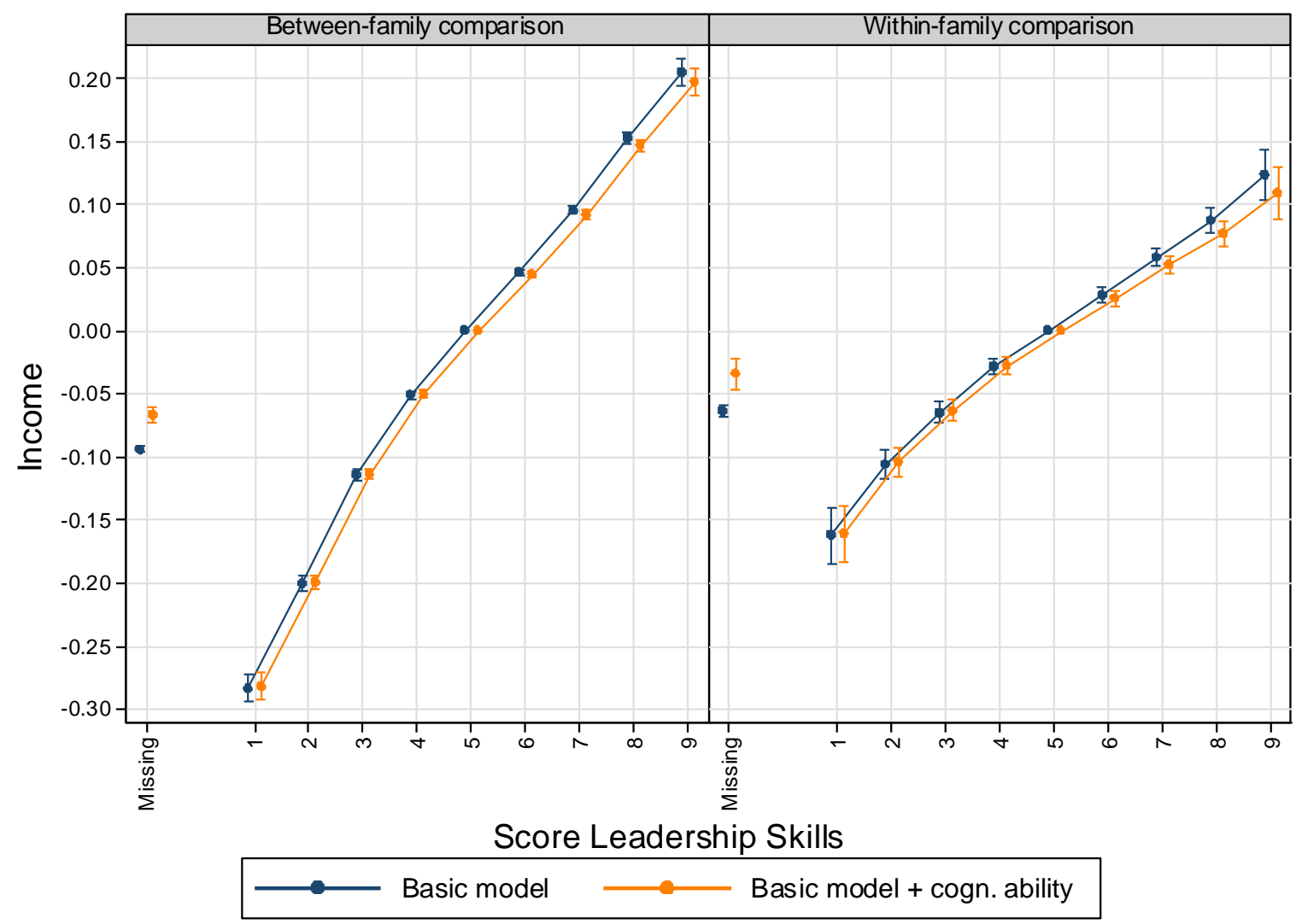

Note: Basic models control for birth year, birth order, and in case of between-family considerations for sibling group size. Results for models including cognitive ability are shown separately. 
Figure A6: The relationship between leadership scores measured at ages 17-20 and probability to obtain tertiary education by age 39 amongst Swedish men born 1963-1979. Linear probability models, error bars are $95 \%$ confidence intervals.

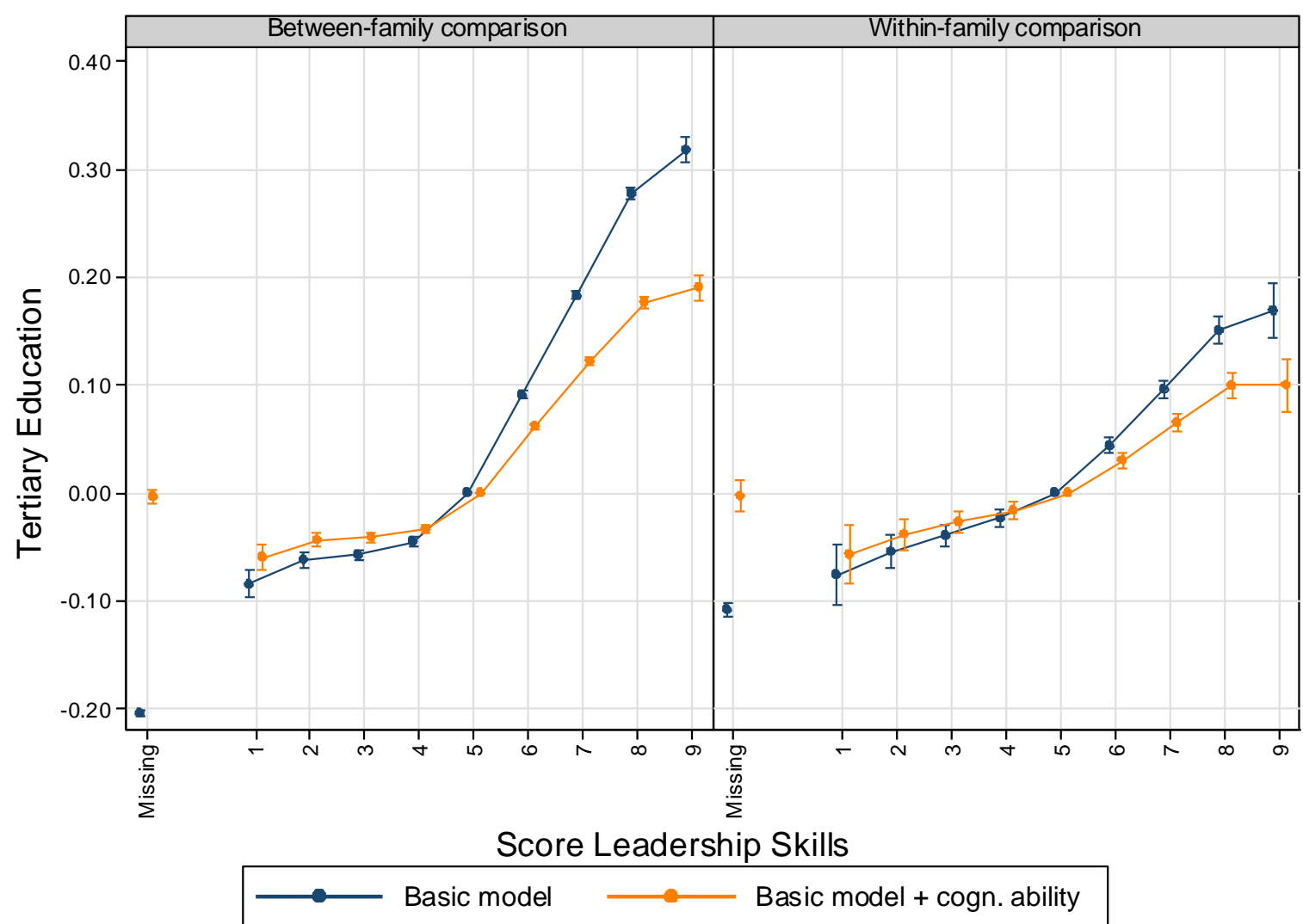

Note: Basic models control for birth year, birth order, and in case of between-family considerations for sibling group size. Results for models including cognitive ability are shown separately. 
Figure A7: The relationship between leadership scores measured at ages 17-20 and the probability to get married by age 39 amongst Swedish men born 1963-1979. Linear probability models, error bars are $95 \%$ confidence intervals.

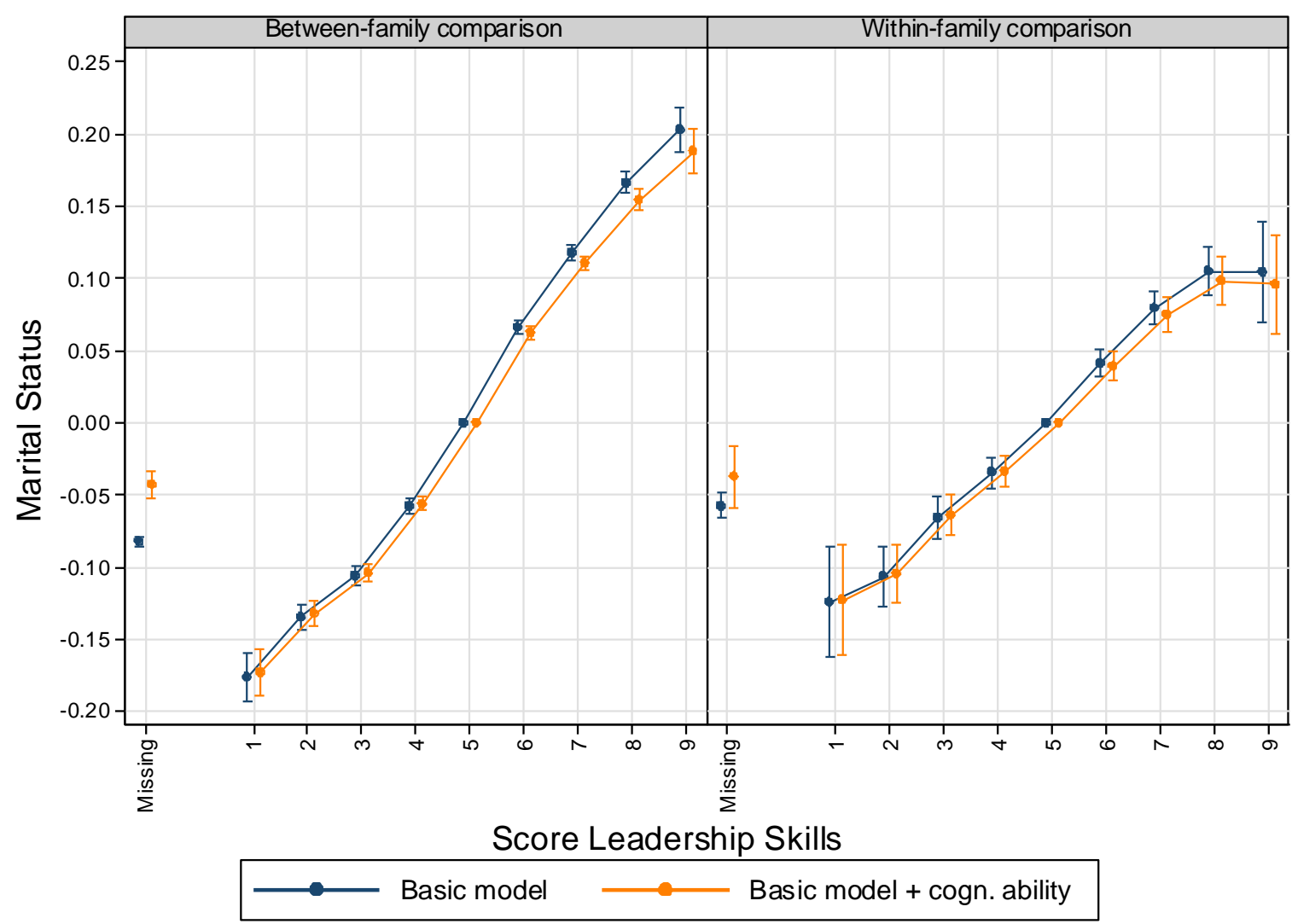

Note: Basic models control for birth year, birth order, and in case of between-family considerations for sibling group size. Results for models including cognitive ability are shown separately. 
Figure A8: The relationship between leadership scores measured at ages 17-20 and probability to remain childless by age 39 or later amongst Swedish men born 1963-1979. Linear probability models by educational levels, error bars are 95\% confidence intervals.

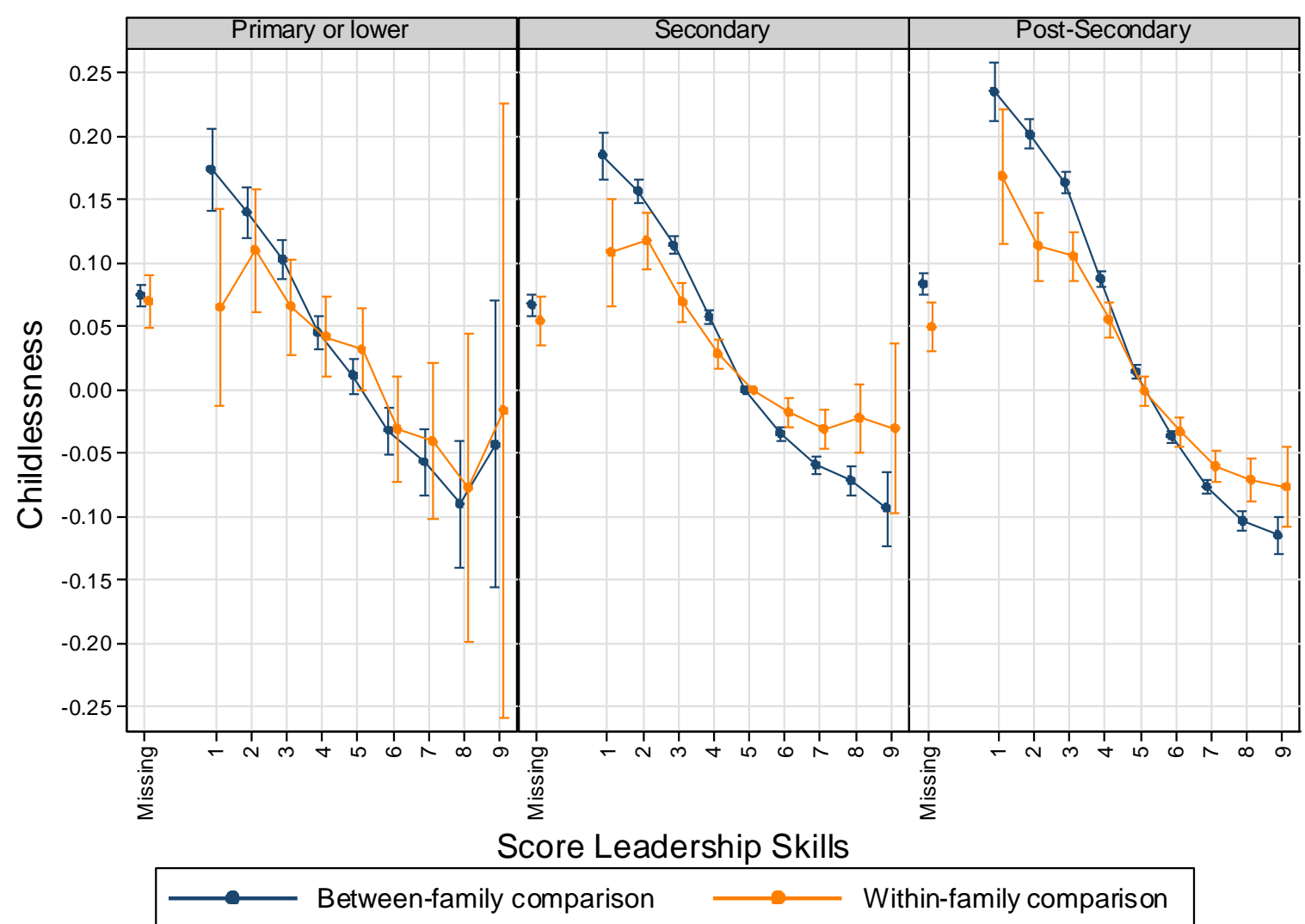

Note: Models control for cognitive ability, birth year, birth order, and in case of between-family considerations for sibling group size. 
Figure A9: The relationship between leadership scores measured at ages 17-20 and total number of children by age 39 and higher amongst Swedish men born 1963-1979. Poisson regression models by income deciles, error bars are $95 \%$ confidence intervals.

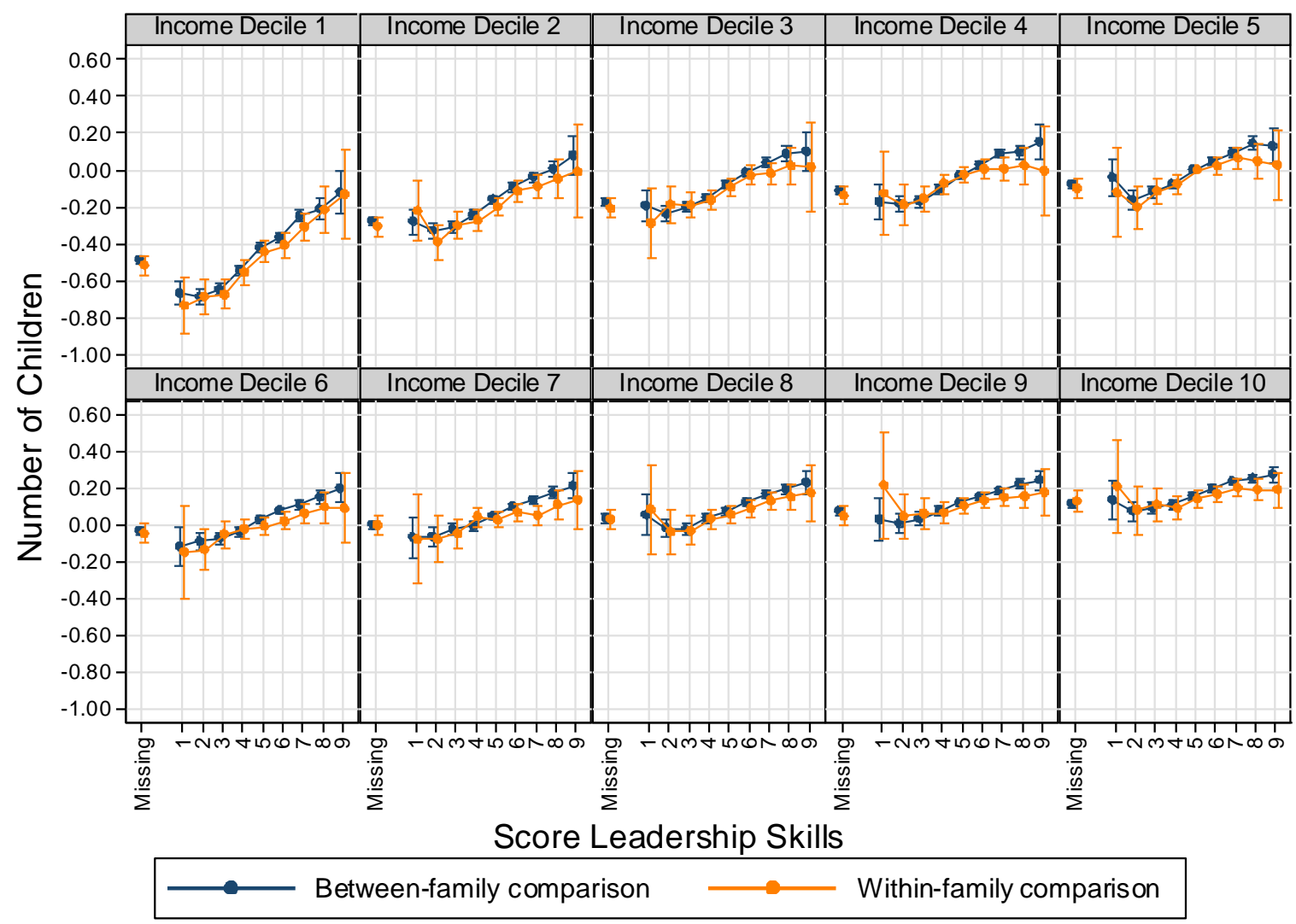

Note: Models control for cognitive ability, birth year, birth order, and in case of between-family considerations for sibling group size. 
Figure A10: The relationship between leadership scores measured at ages 17-20 and total number of children by age 39 and higher amongst Swedish men born 1963-1979. Poisson regression models by educational levels, error bars are 95\% confidence intervals.

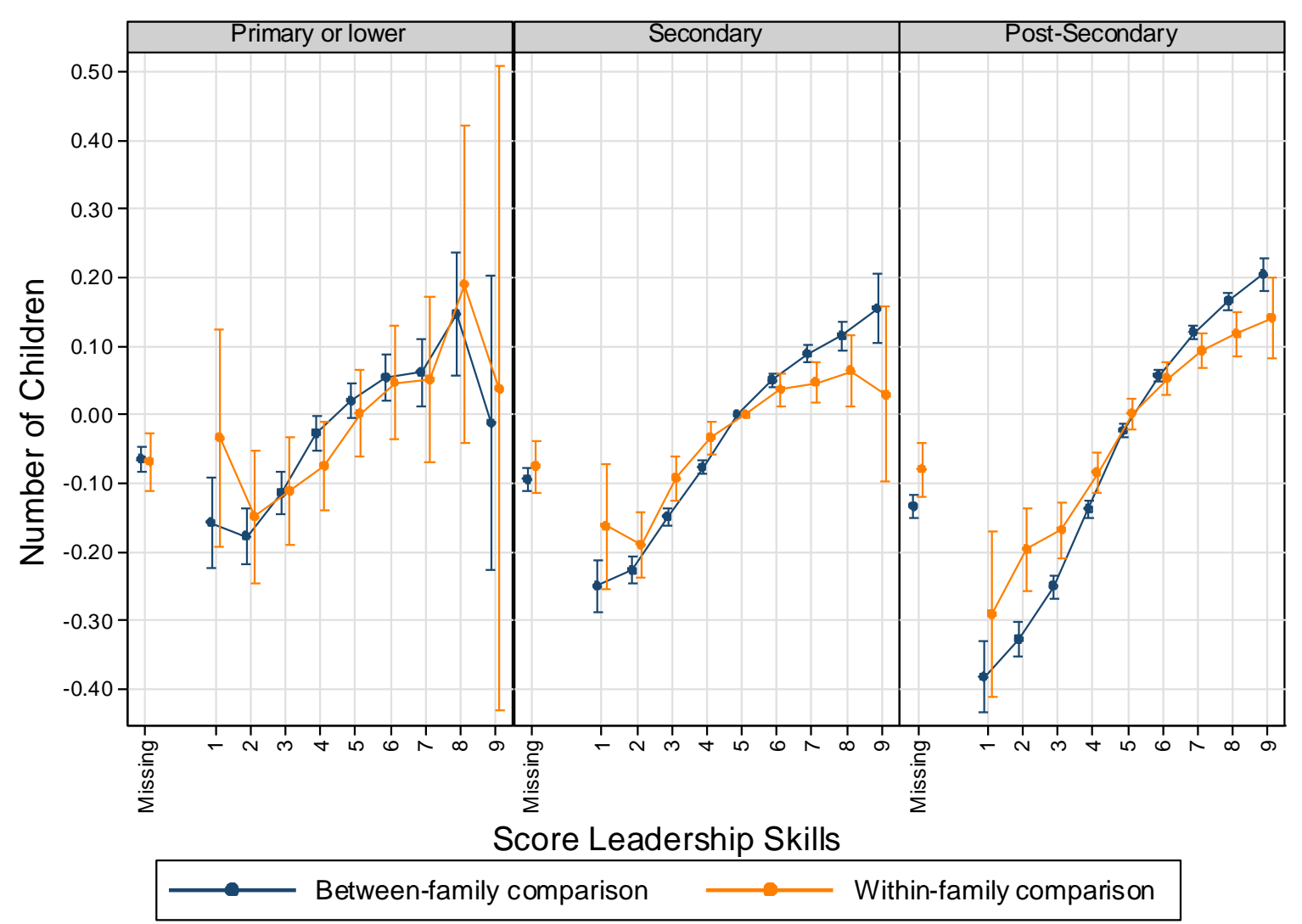

Note: Models control for cognitive ability, birth year, birth order, and in case of between-family considerations for sibling group size. 
Figure A11: The relationship between leadership scores measured at ages 17-20 and total number of children by age 39 and higher amongst Swedish men born 1963-1979. Poisson regression models by marital status, error bars are 95\% confidence intervals.

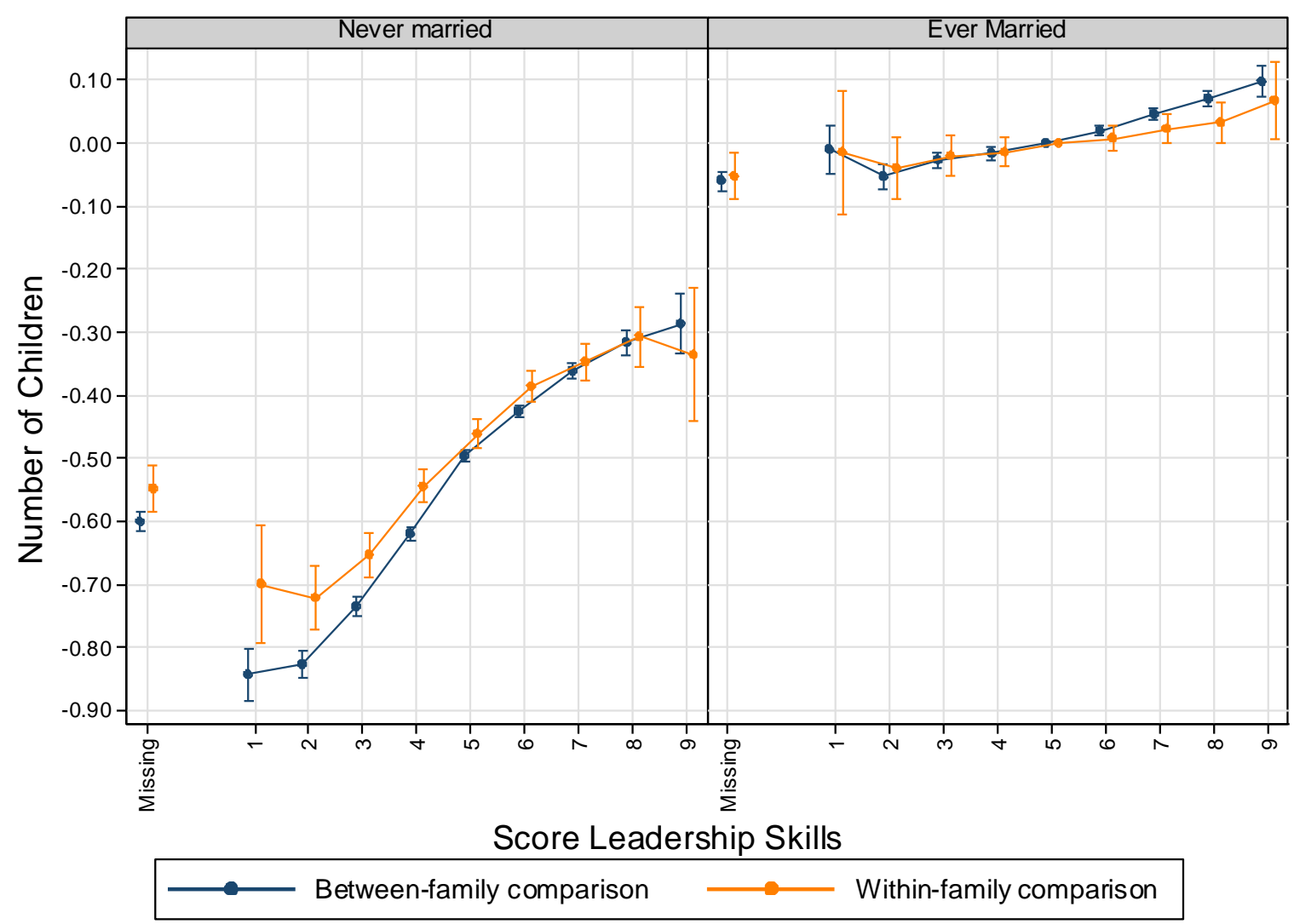

Note: Models control for cognitive ability, birth year, birth order, and in case of between-family considerations for sibling group size. 